Full length article

\title{
Gelatin-based 3D conduits for transdifferentiation of mesenchymal stem cells into Schwann cell-like phenotypes
}

\author{
Metin Uz ${ }^{a}$, Melda Büyüközb ${ }^{b}$, Anup D. Sharma ${ }^{\mathrm{a}, \mathrm{d}}$, Donald S. Sakaguchi ${ }^{\mathrm{d}, \mathrm{e}}$, Sacide Alsoy Altinkaya ${ }^{\mathrm{c}, *}$, \\ Surya K. Mallapragada ${ }^{\mathrm{a}, \mathrm{d}, *}$ \\ a Department of Chemical and Biological Engineering, Iowa State University, Ames, IA 50011, United States \\ ${ }^{\mathrm{b}}$ Department of Biotechnology and Bioengineering, Izmir Institute of Technology, Izmir, Turkey \\ ${ }^{\mathrm{c}}$ Department of Chemical Engineering, Izmir Institute of Technology, Izmir, Turkey \\ ${ }^{\mathrm{d}}$ Neuroscience Program, Iowa State University, Ames, IA 50011, United States \\ ${ }^{\mathrm{e}}$ Department of Genetics, Development and Cell Biology, Iowa State University, Ames, IA 50011, United States
}

\section{A R T I C L E I N F O}

Article history:

Received 14 October 2016

Received in revised form 8 February 2017

Accepted 11 February 2017

Available online 16 February 2017

\section{Keywords:}

3D gelatin conduits

MSCs

SCS

Transdifferentiation

Nerve regeneration

\begin{abstract}
A B S T R A C T
In this study, gelatin-based 3D conduits with three different microstructures (nanofibrous, macroporous and ladder-like) were fabricated for the first time via combined molding and thermally induced phase separation (TIPS) technique for peripheral nerve regeneration. The effects of conduit microstructure and mechanical properties on the transdifferentiation of bone marrow-derived mesenchymal stem cells (MSCs) into Schwann cell (SC) like phenotypes were examined to help facilitate neuroregeneration and understand material-cell interfaces. Results indicated that 3D macroporous and ladder-like structures enhanced MSC attachment, proliferation and spreading, creating interconnected cellular networks with large numbers of viable cells compared to nanofibrous and 2D-tissue culture plate counterparts. 3Dladder-like conduit structure with complex modulus of $\sim 0.4 \times 10^{6} \mathrm{~Pa}$ and pore size of $\sim 150 \mu \mathrm{m}$ provided the most favorable microenvironment for MSC transdifferentiation leading to $\sim 85 \%$ immunolabeling of all SC markers. On the other hand, the macroporous conduits with complex modulus of $\sim 4 \times 10^{6} \mathrm{~Pa}$ and pore size of $\sim 100 \mu \mathrm{m}$ showed slightly lower ( $\sim 65 \%$ for p75, 75\% for S100 and $\sim 85 \%$ for S100 $\beta$ markers) immunolabeling. Transdifferentiated MSCs within 3D-ladder-like conduits secreted significant amounts ( $\sim 2.5 \mathrm{pg} / \mathrm{mL}$ NGF and $\sim 0.7 \mathrm{pg} / \mathrm{mL}$ GDNF per cell) of neurotrophic factors, while MSCs in macroporous conduits released slightly lower $(\sim 1.5 \mathrm{pg} / \mathrm{mL}$ NGF and $0.7 \mathrm{pg} / \mathrm{mL}$ GDNF per cell $)$ levels. PC12 cells displayed enhanced neurite outgrowth in media conditioned by conduits with transdifferentiated MSCs. Overall, conduits with macroporous and ladder-like 3D structures are promising platforms in transdifferentiation of MSCs for neuroregeneration and should be further tested in vivo.
\end{abstract}

\section{Statement of Significance}

This manuscript focuses on the effect of microstructure and mechanical properties of gelatin-based 3D conduits on the transdifferentiation of mesenchymal stem cells to Schwann cell-like phenotypes. This work builds on our recently accepted manuscript in Acta Biomaterialia focused on multifunctional 2D films, and focuses on 3D microstructured conduits designed to overcome limitations of current strategies to facilitate peripheral nerve regeneration. The comparison between conduits fabricated with nanofibrous, macroporous and ladder-like microstructures showed that the ladder-like conduits showed the most favorable environment for MSC transdifferentiation to Schwann-cell like phenotypes, as seen by both immunolabeling as well as secretion of neurotrophic factors. This work demonstrates the importance of controlling the 3D microstructure to facilitate tissue engineering strategies involving stem cells that can serve as promising approaches for peripheral nerve regeneration.

๔) 2017 Acta Materialia Inc. Published by Elsevier Ltd. All rights reserved.

\footnotetext{
* Corresponding author at: Department of Chemical Engineering, Izmir Institute of Technology, Gulbahce Koyu, Urla, Izmir 35430, Turkey (S.A. Altinkaya). Department of Chemical and Biological Engineering, Iowa State University, Ames, IA 50011, United States (S.K. Mallapragada).

E-mail addresses: sacidealsoy@iyte.edu.tr (S.A. Altinkaya), suryakm@iastate.edu (S.K. Mallapragada).
}

\section{Introduction}

The application of cell-based nerve regeneration therapies, has been considered as a promising strategy for the treatment of large 
peripheral nerve injuries. Schwann cells (SCs), which form the myelin sheath around peripheral axons, produce extracellular matrix (ECM) molecules, integrins and trophic factors, such as NGF (nerve growth factor), BDNF (brain-derived neurotrophic factor), and GDNF (glial cell line-derived neurotrophic factor), to enhance guidance and support for regenerating axons. Therefore, SCs are considered an integral component of cell-based nerve regeneration therapies for peripheral nerve regeneration [1-9]. Although a number of studies have demonstrated enhanced axonal regeneration across nerve gaps using nerve conduits implanted with SCs [10-14], the limited availability, donor site morbidity and the slow in vitro growth of SCs restricts the clinical translation of this strategy [15]. As an alternative, in a few recent studies, in vitro differentiated mesenchymal stem cells (MSCs) possessing SC like properties have been explored in different types of conduits for nerve regeneration purposes [16-19].

Mesenchymal stem cells, isolated and derived from various connective tissue sources (e.g., bone marrow, adipose tissue, placenta, umbilical cord blood) [7], hold considerable potential for cell-based nerve regeneration therapies using autologous transplantation due to accessibility, plasticity, multipotent nature, differentiation ability into functional cell types, paracrine activity via secretion of bioactive molecules including neurotrophic factors such as, NGF, BDNF and GDNF $[20,21]$ and lack of ethical concerns [15,22-27]. Among those sources, bone marrow-derived MSCs are considered as the most available cell type and designated as the gold standard, although MSCs derived from other sources (adipose tissue, placenta, umbilical cord blood etc.) have also shown promising potential for proliferation and differentiation into different cell types [28]. Various studies have suggested strategies for neuronal differentiation and in vivo transplantation of MSCs in order to treat peripheral nerve damage [29-32] and numerous benefits of using transdifferentiated MSCs have been reported including promotion of axonal regeneration, reduced lesion size, enhanced neuronal survival and improved functional outcomes [33-40]. The benefits of MSC differentiation for Wallerian degeneration and nerve regeneration also include superior in vivo viability, enhanced neurotrophic factor secretion and myelinating ability [41]. However, current difficulties in controlling the final fate of the implanted cell population and providing scalable differentiation protocols along with an ideal 3D matrix mimicking the ECM, limit the clinical use of MSCs [42,43]. The positive effects of undifferentiated MSCs, circumventing the limitations of differentiation procedures and clinical applicability, have also been reported. However, the transplantation of undifferentiated cells may cause in vivo differentiation of MSC into unwanted and non-neural cell lineages in response to local stimuli or other dominant cells in the area [41].

The differentiation of MSCs depends on multiple interacting factors in their microenvironment, including biological, chemical and physical cues which, in combination, result in a complicated differentiation behavior outcomes [44-51]. Recently, specific composition of the differentiation media, as well as mechanical properties of the ECM, such as structure, composition and elasticity, have been demonstrated to influence MSC differentiation [50,52-55]. For instance, matrix stiffness has been found to regulate the differentiation of MSCs into specific lineages indicating that softer substrates promote neurogenic, adipogenic and chondrogenic fates, while stiffer substrates enhance myogenesis and osteogenesis $[45,51,56-61]$. The dimension in which cells are cultured is also a crucial factor in determining the differentiation properties of the cells. The current understanding of most biological mechanisms, including differentiation, has been garnered from cells cultured on two-dimensional (2D) surfaces. Most studies examining MSC transdifferentiation have relied on 2D tissue culture plates, after which the cells are then seeded into various types of scaffolds for facilitating neural regeneration, leading to extra treatment steps, time, effort and cost $[16,17,20,21]$. The cells naturally exist in a complex ECM containing various components, mixed cell populations and cell-secreted factors, hence, employing a 3D culture model is more relevant to the physiological condition to explore cell-cell and cell-matrix interactions affecting transdifferentiation. Current knowledge with respect to the influences of mechanical and structural properties of 3D scaffolds on the transdifferentiation behavior of MSCs is significantly limited and should be expanded [62]. Most of the previous studies investigated the effect of matrix properties on the osteogenic differentiation of MSCs; on the other hand, only a few studies focused on the relationship between matrix properties and the differentiation of MSCs into SC like phenotypes [56,63-66].

Taking these motivations into account, in this study, gelatin based 3D porous conduits with ladder-like (LL), macroporous (MP) and nanofibrous (NF) structures were developed in order to directly transdifferentiate bone marrow-derived MSCs into SClike phenotypes within the conduits for the treatment of large peripheral nerve gaps. This strategy was used to enhance the directed transdifferentiation of MSCs within a 3D conduit matrix and prevent unnecessary additional steps involving transdifferentiation in regular 2D cultures followed by implantation. Combined molding and thermally induced phase separation (TIPS) techniques were selected to manufacture different microstructured 3D matrices which are difficult to achieve by current electrospinning and self-assembly techniques [67,68]. The effects of conduit structure, morphology and mechanical properties on differentiation and paracrine activity of MSCs (secretion of neurotrophic factors such as NGF, BDNF and GDNF) were investigated, and the performance of $3 \mathrm{D}$ conduits were compared with their 2D cell culture plate counterparts. The paracrine activity of transdifferentiated MSCs in the conduits was assessed not only by detecting the released neurotrophic factors but also by measuring their biological activity through the evaluation of neurite extension on PC12 cells cocultured with the MSCs across a porous membrane insert. The overall results indicated that the conduits prepared in this study with controlled structural properties can serve as promising candidates for 3D ECM platforms intended for nerve regeneration applications and can be further tested in vivo.

\section{Material and methods}

\subsection{Materials}

Type B gelatin from bovine skin, 1-ethyl-3-(3-dimethylaminopropyl) carbodiimide $\mathrm{HCl}$ (EDC), N-hydroxysuccinimide (NHS), (2-(N-morpholino) ethanesulfonicacid) hydrate (MES), Bovine serum albumin (BSA), all-trans-retinoic acid (ATRA) and $\beta$-mercaptoethanol (BME) were obtained from Sigma Aldrich. 1, 4-dioxane, acetone, ethanol were obtained from Merck. The cell culture media components, minimum essential medium $(\alpha-$ MEM) and L-glutamine were obtained from Gibco. Fetal bovine serum (FBS) was purchased from Atlanta Biologicals and antibiotic-antimycotic was obtained from Invitrogen. The transdifferentiation components forskolin (FSK) and heregulin $\beta 1$ (HRG) were purchased from EMD Millipore, while platelet derived growth factor (PDGF) and basic fibroblast growth factor (bFGF) were obtained from Sigma and Promega, respectively. Triton X-100 and paraformaldehyde were supplied from Fisher Scientific. The primary antibodies, calcium binding protein Rabbit- $\alpha-S 100$ and Mouse- $\alpha-S 100 \beta$ were obtained from Abcam while low-affinity neurotrophin receptor Rabbit- $\alpha$-p75 was obtained from Promega. The secondary antibodies, Donkey- $\alpha$-Mouse-Cy3 and Donkey$\alpha$-Rabbit-Cy3 were purchased from ImmunoResearch while DAPI (4',6-diamidino-2-phenylindole) was obtained from Invitrogen. 


\subsection{Methods}

\subsubsection{Fabrication of gelatin nerve conduits}

In this study, a combination of molding and thermally induced phase separation (TIPS) techniques was used to fabricate three conduits with different microstructures. With TIPS, preparation of several different microstructures was accomplished while molding allowed obtaining 3D shape of the conduits. In the TIPS technique, demixing is usually stimulated by either loading the solution below a binodal solubility curve or exposure of the solution to an immiscible solvent [69]. Therefore, temperature and solvent/non-solvent ratios are important parameters to obtain phase separation and different microstructures. The strategy here was to fix the phase separation temperature and gelation concentration at $-20^{\circ} \mathrm{C}$ and $5 \%$, respectively and change the solvent/nonsolvent ratio in order to obtain different microstructured conduits. The type of conduits prepared, their solvent/non-solvent ratio and phase separation temperature are indicated in Table 1.

To create conduits, the mold was first assembled by inserting a long Teflon capillary $(2.0 \mathrm{~mm}$ in diameter $)$ into a Teflon tube (3.8 $\mathrm{mm}$ in diameter) (Supplementary Information Figure S.1). As different from the commercially available single lumen nerve guidance conduits, the diameter and size of these conduits can easily be adjusted through changing the dimensions of the mold capillary and tube providing the flexibility to obtain conduits with different dimensions by preserving their original microstructure. 5\% $(\mathrm{w} / \mathrm{v})$ gelatin solutions were prepared at $55^{\circ} \mathrm{C}$ by dissolving gelatin in 70/30 (v/v) water/ethanol for NF, 85/15 (v/v) water/ethanol for $\mathrm{MP}$ and water for LL conduit. Then, gelatin solution was injected into the mold and was kept at $-20^{\circ} \mathrm{C}$ for phase separation for $5 \mathrm{~h}$ and incubated in cold ethanol $\left(-18^{\circ} \mathrm{C}\right)$ overnight. Following the incubation, the capillary and conduit were removed from the mold and the samples were immersed in nonsolvent, 1, 4-dioxane, for 2 days and freeze-dried for 3 days. In this process, nonsolvent ethanol was used to exchange water (solvent) from the system and detach conduits from the mold while nonsolvent 1,4 dioxane was used to stabilize obtained structures during lyophilization. It is known that nonsolvent must possess relatively high melting temperature to avoid melting during lyophilization, allow facile removal of sublimation and keep nanofiber structure [70]. 1ethyl-3-(3-dimethyl-aminopropyl) carbodiimide $\mathrm{HCl}$ (EDC) with $\mathrm{N}$-hydroxy-succinimide (NHS) were used as cross-linkers of gelatin conduits with NHS to EDC molar ratio of 0.2 . The reaction was carried out in (2-(N-morpholino) ethanesulfonicacid) hydrate (MES) buffer ( $\mathrm{pH} 5.3,0.05 \mathrm{M}$ ) at $4^{\circ} \mathrm{C}$ for $24 \mathrm{~h}$. After the cross-linking reaction, conduits were washed with distilled water at $37^{\circ} \mathrm{C}$ for 3 times. Acetone/water with a ratio of $90 / 10(\mathrm{v} / \mathrm{v})$ was used instead of pure water to protect the nanofibrous structure [71]. Next, conduits were frozen at $-18{ }^{\circ} \mathrm{C}$ for $12 \mathrm{~h}$, freeze-dried for 2 days and stored in a desiccator for later use.

\subsubsection{Characterization of nerve conduits}

The morphology of conduits was examined by scanning electron microscopy (SEM) on a Philips XL-30SFG model. The samples

Table 1

The type of the conduits prepared, solvent/non-solvent ratio and phase separation temperature.

\begin{tabular}{cll}
\hline Type of Conduit & $\begin{array}{l}\text { Solvent/Non-solvent } \\
\text { Ratio }\end{array}$ & $\begin{array}{l}\text { Phase Separation } \\
\text { Temperature }\end{array}$ \\
\hline Nanofibrous (NF) & $\begin{array}{l}70 / 30(\mathrm{v} / \mathrm{v}) \text { Water } / \\
\text { Ethanol }\end{array}$ & $-20{ }^{\circ} \mathrm{C}$ \\
Macroporous & $\begin{array}{l}85 / 15(\mathrm{v} / \mathrm{v}) \text { Water } / \\
\text { Ethanol }\end{array}$ & $-20^{\circ} \mathrm{C}$ \\
Ladder Like (LL) & $100 \%$ Water & $-20^{\circ} \mathrm{C}$ \\
\hline
\end{tabular}

were coated with gold using a Magnetron Sputter Coating Instrument.

Pore sizes of the conduits were measured by using Image J software while the porosities, $\varepsilon$, were calculated using Eq. (1) where $D_{p}$ is the skeletal density of gelatin conduit, and $D_{0}$ is the density of gelatin. For gelatin type B (from calf skin, approx. 225 Bloom), $\mathrm{D}_{0}=1.35 \mathrm{~g} / \mathrm{cm}^{3}[62]$.

$\varepsilon=1-\mathrm{D}_{\mathrm{p}} / \mathrm{D}_{\mathrm{o}}$

$\mathrm{D}_{\mathrm{p}}=\mathrm{m} / \mathrm{V}$

where $\mathrm{m}$ is measured mass (weight) of conduit and $\mathrm{V}$ is volume of conduit determined from the diameter and height of the conduits.

The swelling ratio (SR) of the conduits was also evaluated. Prior to the swelling study, the dry conduit samples were cut into $1 \mathrm{~cm}$ lengths and weighed. Then, they were immersed into $3 \mathrm{~mL}$ of phosphate buffer saline (PBS) at $\mathrm{pH} 7.4$ and incubated at $37^{\circ} \mathrm{C}$ for $24 \mathrm{~h}$. After incubation, the samples were removed from PBS, blotted with Kim-wipes to remove excess water from the conduit surfaces and weighed. The swelling degree (SR) was calculated as:

$S R=\frac{W_{d r y}-W_{\text {wet }}}{W_{d r y}} \times 100$

where $W_{d r y}$ and $W_{\text {wet }}$ are the sample weights before and after swelling, respectively.

The mechanical properties of conduits were determined on an Ares-G2 rheometer (TA Instruments) as described elsewhere [66]. The $2 \mathrm{~cm}$ length cylindrical conduits, previously immersed in PBS at $37^{\circ} \mathrm{C}$ for $24 \mathrm{~h}$, were placed between two parallel stainless steel plates with a $10 \mathrm{~mm}$ gap at $37^{\circ} \mathrm{C}$. A dynamic strain sweep test (with amplitudes ranging between $0.01 \%$ and $10 \%$ ) was conducted at a frequency of $1 \mathrm{~Hz}$ to measure the dynamic shear modulus and detect the linear viscoelastic region for the conduits. Following the detection of the linear viscoelastic region, a dynamic frequency sweep test (with frequency ranging between $0.01 \mathrm{~Hz}$ and $10 \mathrm{~Hz}$ ) was carried out at a fixed strain in linear viscoelastic region to measure the dependence of the dynamic shear modulus and the loss factor on frequency. The storage modulus $\left(\mathrm{G}^{\prime}\right)$ and the loss modulus $\left(G^{\prime \prime}\right)$ were obtained from the measurements as a function of the strain amplitude or the frequency. The complex modulus magnitude $\left(G^{*}\right)$, which is a measure of stiffness $\left(\left|G^{*}\right|^{2}=\left(G^{\prime}\right)^{2}+\right.$ $\left.\left(G^{\prime \prime}\right)^{2}\right)$, and the loss factor $\left(\tan \delta \equiv\left(G^{\prime \prime}\right) /\left(G^{\prime}\right)\right.$, which is a measure of internal energy dissipation, were also determined as a function of the strain amplitude or the frequency. The same test on the conduits was conducted after incubation in cell culture media at $37{ }^{\circ} \mathrm{C}$ under $5 \% \mathrm{CO}_{2}$ atmosphere during 15 days in order to test the mechanical stability.

\subsubsection{Cell culture}

Brown Norway rat MSCs isolated as described in our previous work [19] were grown in maintenance medium (MM) composed of minimum essential medium ( $\alpha$-MEM, Gibco BRL) supplemented with $20 \%$ fetal bovine serum (FBS; Atlanta Biologicals), $4 \mathrm{mM} \mathrm{L}-$ glutamine (Gibco), and antibiotic-antimycotic (Invitrogen) and incubated at $37{ }^{\circ} \mathrm{C}$ and $5 \% \mathrm{CO}_{2}$ environment. Sub-culturing was conducted every 2-3 days when the cells reached $80 \%$ confluency as described previously [19]. The cells on passage number two were used for transdifferentiation experiments. In the experiments, XenoFree cell culture medium that is completely free from human and animal-derived components was not used since the focus of this study is to provide the in vitro proof of concept. However, in future experiments, the possible use of XenoFree cell culture medium can be explored before the in vivo and clinical studies. 
2.2.4. In vitro transdifferentiation of rat MSCs into SC-like phenotypes 2.2.4.1. Transdifferentiation procedure. In vitro chemical transdifferentiation of rat MSCs into SC-like phenotypes was performed by following the previously mentioned protocols [19,27]. Rat MSCs were grown in MM for 1-2 days in T75 flasks at $37{ }^{\circ} \mathrm{C}$ and $5 \%$ $\mathrm{CO}_{2}$ atmosphere. Once the cells reached $60-70 \%$ confluency, the MM media was replaced with transdifferentiation media-1 (TDM-1) containing $\alpha$-MEM supplemented with $1 \mathrm{mM} \quad \beta$ mercaptoethanol (BME; Sigma Aldrich, St. Louis, MO, USA) and incubated for one day at $37{ }^{\circ} \mathrm{C}$ and $5 \% \mathrm{CO}_{2}$ atmosphere. TDM-1 was then replaced with TDM-2 containing $\alpha$-MEM, 10\% FBS and $35 \mathrm{ng} / \mathrm{mL}$ all-trans-retinoic acid (ATRA; Sigma) and incubated in TDM-2 for 3 days at $37{ }^{\circ} \mathrm{C}$ under $5 \% \mathrm{CO}_{2}$ atmosphere. Following 3 days of incubation, TDM-2 was replaced by TDM-3 containing $\alpha$-MEM, 10\% FBS, $5 \mu \mathrm{M}$ forskolin (FSK; EMD Millipore, Billerica, MA, USA), $5 \mathrm{ng} / \mathrm{mL}$ platelet derived growth factor (PDGF; Sigma), $10 \mathrm{ng} / \mathrm{mL}$ basic fibroblast growth factor (bFGF, Promega Corporation, Madison, WI, USA) and $200 \mathrm{ng} / \mathrm{mL}$ heregulin $\beta 1$ (HRG; Calbiochem, EMD Millipore) and incubated at $37^{\circ} \mathrm{C}$ under $5 \% \mathrm{CO}_{2}$ atmosphere for 8 days. Cells were washed with PBS prior to each media change.

2.2.4.2. Immunocytochemical (ICC) analysis. At the end of the transdifferentiation procedure, the undifferentiated (uMSCs) control cells and transdifferentiated (tMSCs-2D) cells, possessing SC-like phenotype, were seeded into 96-well plates (2000 cells/well) and immunocytochemical (ICC) analysis was applied to characterize the uMSCs and tMSCs-2D. During the ICC analysis, the cells in the 96-well plates were rinsed with PBS and fixed with 4\% paraformaldehyde for $20 \mathrm{~min}$ at room temperature. The cells were then rinsed with PBS 3 times and incubated in blocking buffer composed of $5 \%$ normal donkey serum (NDS, Jackson ImmunoResearch, West Grove, PA, USA), 0.4\% bovine serum albumin (BSA; Sigma) and $0.2 \%$ Triton X-100 (Fisher Scientific) in PBS for one hour. Several antibodies including glial cell markers, calcium binding protein Rabbit- $\alpha-S 100$, Mouse- $\alpha-S 100 \beta$ (Abcam-ab11178), low-affinity neurotrophin receptor Rabbit- $\alpha$-p75 (PromegaG3231) and Neuron-specific class III beta-tubulin, Mouse- $\alpha$-Tuj1, were used for ICC analysis. Following the incubation in blocking buffer, the cells were further incubated with primary antibodies at $4^{\circ} \mathrm{C}$ overnight. On the following day, the cells were rinsed with PBS for 4 times and subsequently incubated in corresponding secondary antibodies, Donkey- $\alpha$-Mouse-Cy3 (1:500, Jackson ImmunoResearch), Donkey- $\alpha$-Rabbit-Cy3 (1:500, Jackson ImmunoResearch), and DAPI (4',6-diamidino-2-phenylindole) (1:2000, Invitrogen) for nuclei staining, all diluted in the same blocking solution. The cells were incubated for $90 \mathrm{~min}$ in the dark at room temperature and then rinsed with PBS for 3 times before the fluorescence microscopy imaging.

2.2.4.3. Effect of $3 D$ conduits on cell morphology, proliferation, spreading and interconnection. The effect of different 3D conduits on their ability to impact cell morphology, proliferation, spreading and formation of interconnections was examined. The following differentiation paradigms were compared: 1) tMSCs-2D (previously transdifferentiated into SC like phenotype in a T75 flask) and 2) uMSCs (undifferentiated MSCs) growing in different 3D gelatin conduits. Cells growing on standard 2D tissue culture polystyrene plates (2D TCPS) served as the control condition. The tMSCs-2D and uMSCs were seeded in the lumen of each conduit (LL, MP and NF) with a cell density of $1 \times 10^{4}$ cell $/ \mathrm{cm}^{2}$. The $20 \mu \mathrm{L}$ of concentrated cell suspension $\left(2 \times 10^{5}\right.$ cells per $\left.100 \mu \mathrm{L}\right)$ was injected directly into the conduit lumen and incubated 3-5 min for the integration of the cells into the conduit structure. During this step, the cells diffused into the conduit microstructure through the continuous pore network starting from the inner lumen of the conduits. This procedure was repeated 5 times (until all the cell suspension was absorbed by the conduits) to ensure that cells disperse within the 3D conduit structure and inner lumen rather than adhering to the wells or outside of the conduits. Then, the cells were allowed to attach to the conduit microstructure for $6 \mathrm{~h}$ before transferring the conduit to a well in a 6-well plate filled with culture media. After 1 and 5 days of growth, the samples were immunolabeled with the Mouse- $\alpha$-Tuj1 antibody (see above) and co-labeled with Rhodamine Phalloidin to detect the cellular morphology, proliferation, spreading and interconnection within the 3D conduits.

2.2.4.4. Effect of $3 D$ conduits on mesenchymal stem cell transdifferentiation. The uMSCs were seeded in the lumen of each conduit (LL, MP and NF) with a cell density of $1 \times 10^{4} \mathrm{cell} / \mathrm{cm}^{2}$ as mentioned in Section 2.2.4.3 to test the performance of the developed 3D conduits on cell transdifferentiation. To compare the efficacy of $3 \mathrm{D}$ environment versus the $2 \mathrm{D}$, the same density of cells were also seeded in 2D tissue culture polystyrene (2D TCPS) 6-well plates as controls and the same transdifferentiation protocol was applied. The cells (uMSCs) transdifferentiated in 2D TCPS plates and T-75 flasks were mentioned as tMSCs-2D. The same chemical transdifferentiation procedure and ICC analysis described above were applied to evaluate the differentiation behavior of cells on different substrates. The cells (uMSCs) directly transdifferentiated within 3D gelatin conduits possessing different microstructures were mentioned as tMSCs, while the uMSCs transdifferentiated in T75 flasks and 2D TCPS plates were mentioned as tMSCs-2D throughout the text. At the end of the ICC analysis, the 3D conduits with tMSCs were cut into thin slices in cross-section and mounted onto glass slides for fluorescence microscopy imaging in order to observe the cells present not only on the inner lumen of the conduits but also within the 3D conduit microstructure. After the collection of images, the number of cells immunostained with the SCS markers were counted with respect to the total number of cells (based on DAPI-stained nuclei) in the images to calculate the percentage of immunostained cells.

\subsubsection{Paracrine activity of tMSCs}

The neurotropic factor secreting capacity of tMSCs differentiated in each of the 3D conduits (LL, MP and NF) were evaluated by measuring released NGF, BDNF and GDNF over a 15 day period. For this purpose, uMSCs (density of $1 \times 10^{4} \mathrm{cell} / \mathrm{cm}^{2}$ ) were seeded in the lumen of each conduit and the transdifferentiation procedure, described above, was applied. The same procedure was also applied for the same cell density of uMSCs seeded on a 2D TCPS 6-well plate as control. At the end of the transdifferentiation process, the tMSCs present in the lumen of conduits and 2D TCPS 6well plate were incubated in $3 \mathrm{~mL} \mathrm{MM}$ at $37{ }^{\circ} \mathrm{C}$ under $5 \% \mathrm{CO}_{2}$ atmosphere for 15 days. The MM was collected every three days and the released NGF, BDNF and GDNF amounts were detected through corresponding ELISA kits (Abcam Rat Beta NGF ELISA kit ab100757 and Promega BDNF and GDNF Emax ${ }^{\circledR}$ ImmunoAssay Systems) by following the manufacturer's protocol. At the end of 15 days, the cell viability of the present tMSCs was also evaluated through CellTiter 96 non-reactive proliferation assay (Promega) by following the manufacturer's procedure.

The bioactivity of the secreted neurotrophic factors from tMSCs present in the conduit lumen was also evaluated using PC12 cells. PC12 cells were grown in RPMI-1640 media supplemented with $10 \%$ horse serum (HS) and $5 \% \mathrm{FBS}$ at $37{ }^{\circ} \mathrm{C}$ under $5 \% \mathrm{CO}_{2}$ atmosphere and sub-cultured every two days. After reaching $70-80 \%$ confluency, the PC12 cells (density of $1 \times 10^{4}$ cell $/ \mathrm{cm}^{2}$ ) were harvested and seeded on mouse laminin coated 6-well plates and incubated at $37{ }^{\circ} \mathrm{C}$ under $5 \% \mathrm{CO}_{2}$ atmosphere for $24 \mathrm{~h}$. Then, the conduits bearing tMSCs (density of $1 \times 10^{4} \mathrm{cell} / \mathrm{cm}^{2}$ ) within the 
lumen were placed on $0.4 \mu \mathrm{m}$ pore size cell inserts (Corning transwell inserts Product \#3412). The inserts were placed above PC12 cells seeded in 6-well plates containing $3 \mathrm{~mL}$ of co-culture media composed of $70 \%$ PC12 cell culture media (RPMI-1640 supplemented with $10 \%$ HS and 5\% FBS) and 30\% of MM. The tMSCs in conduits and PC12 cells were co-cultured for $72 \mathrm{~h}$ at $37{ }^{\circ} \mathrm{C}$ under $5 \% \mathrm{CO}_{2}$ atmosphere. At the end of this incubation, the inserts were removed and the neurite extension of PC12 cells were visualized under fluorescence microscopy after ICC analysis using primary antibody Tuj1 and secondary Alexa Fluor 488 (1:1000, Molecular Probes-Life Technologies, Carlsbad, CA, USA). The quantitative imaging of all the PC12 cells was conducted using an ImageXpress Micro high content imaging system (Molecular Devices) and length of neurites for various conditions was quantified using the neurite outgrowth module of MetaXpress software (Molecular Devices) as mentioned in our previous studies [19,72].

\subsubsection{Statistical analysis}

Throughout this study, the significant differences between the groups were evaluated using ANOVA analysis by Tukey's method with $95 \%$ confidence interval. The results are presented as average \pm standard deviation calculated from at least three independent experiments.

\section{Results}

\subsection{The morphology, microstructure and mechanical properties of conduits}

The general appearance of conduits was observed to be similar as represented in Figure S.1. in Supplementary Information. MP and LL conduits were transparent while in contact with water whereas NF conduits had an opaque white color and nontransparent nature. In the production of NF conduits, phase separation occurred in the spinodal decomposition region in which the polymer (gelatin) and solvent-nonsolvent (water-ethanol) mixture was initially miscible. In this region, a second phase grew spontaneously, without thermodynamic or energetic barriers [73], therefore producing more intense phase separation and completely interconnected continuous nanopores. The $\mathrm{NF}$ conduits (Fig. $1 \mathrm{~A}-\mathrm{C}$ ) prepared with the water/ethanol ratio of $70 / 30(\mathrm{v} / \mathrm{v})$ have nanofibers with $774.8 \mathrm{~nm}$ in length and $187.7 \mathrm{~nm}$ in diameter, which mimic the natural ECM with the fiber diameter changing between 50 and $500 \mathrm{~nm}$ [62]. The increase in solvent nonsolvent ratio from $70 / 30(\mathrm{v} / \mathrm{v})$ to $85 / 15(\mathrm{v} / \mathrm{v})$ promoted polymer-solvent (gelatin-water) interaction resulting in loss of nanofiber microstructure and formation of macroporous microstructure as liquid-liquid phase separation occurred (Fig. 1C-D). The closed pore structures were the result of another phase separation mechanism in which polymer-lean phase disperses in the matrix of polymer-rich phase by nucleation and growth [59]. When pure water was used as solvent instead of water/ethanol mixture, a ladder-like microstructure was achieved (Fig. 1G-I).

Average pore size of the conduits measured from SEM pictures along with their porosities and swelling ratios are shown in Fig. 2. The percent porosity of the NF conduits was found slightly higher ( $\sim 95 \%)$, while their pore sizes were significantly lower $(\sim 100 \mu \mathrm{m}$ for MP and $\sim 150 \mu \mathrm{m}$ for LL) than those of MP and LL conduits. It was observed that the change in the microstructure, porosity and pore size of the conduits significantly affected their water swelling capacity (Fig. 2A and B). As illustrated in Fig. 2B, the change in structure from nano-fibrous (NF) to ladder-like (LL) resulted in a significant increase in swelling ratio. This is due to presence of large pores in the lumen of conduit and throughout the crosssection which can allow effective diffusion of water and absorb more water [74]. This result suggests that the increase in pore size was the determining factor in the swelling capacity of the conduits rather than the porosity, since percent porosities of the conduits were very close to each other. The swelling ratios of MP and LL conduits were found similar in addition to their pore sizes and percent porosities (Fig. 2A and B).

At water/ethanol ratio of $70 / 30(v / v)$, liquid-liquid phase separation occurred at phase separation temperature higher than the freezing point of the polymer solvent mixture causing the formation of small pores with a high porosity. As the freezing point of the polymer solvent mixture approaches the phase separation temperature with an increase in water/ethanol ratio, the liquidliquid phase separation leads to formation of larger pores with lower porosity as in the case of MP conduits. The microstructure observed in LL conduits is a consequence of the solid-liquid phase separation, where polymer solution quenches below the freezing point of the solvent, producing a porous and channeled structure. When the temperature of the polymer solution is lower than the freezing point of the solvent, the crystallization of the solvent takes place and the polymer phase is expelled from the crystallization fronts as impurities. A continuous polymer-rich phase with pores and channels is formed by aggregation of polymer expelled from every single solvent crystal [67]. The direction of channels in the structure is parallel to the direction of heat transfer. This technique has been used in guided regeneration applications, such as scaffolds for spinal cord injury $[75,76]$ and transplantation sheets for retina [77-79], but has never been applied for MSCs differentiation into SC like phenotype.

It was previously reported that not only intrinsic factors, but also extrinsic and effective mechanical factors have a strong influence on the regulation of stem cell fate [80]. In most of the recent studies, the influence of effective storage, loss and complex moduli on the cell fate were also investigated and compared [66,81-86]. Considering these studies, we used rheometry under similar conditions for the measurement of effective moduli in order to demonstrate the effect of storage moduli on stem cell fate. The microstructure of the conduits (porosity, pore size and swelling ratio) affected their mechanical properties of the conduits. All of the conduits, regardless of the microstructural differences, displayed an elastic behavior with storage modulus $\left(G^{\prime}\right)$ higher than the loss modulus $\left(\mathrm{G}^{\prime \prime}\right)$ as shown in Fig. $3 \mathrm{~A}$ and $\mathrm{B}$. In addition, the $G^{\prime}$ and $G^{\prime \prime}$ values remained independent of the strain amplitude for each conduit confirming the linear viscoelastic behavior (Fig. 3A). The NF conduits possessed the highest $\mathrm{G}^{\prime}$ and $\mathrm{G}^{\prime \prime}$ values sequentially, followed by MP and LL conduits due to their lower mesh size with stronger fibrous network (Fig. 1A-C) compared to MP and LL conduits. Pore size and connectivity of the pores are the primary factors controlling the mechanical properties of the conduits.

The average complex modulus $\left(\mathrm{G}^{*}\right)$, which is a measure of the stiffness, and the loss factor $(\tan \delta)$, which is a measure of the internal energy dissipation, were calculated and tabulated in Table 2 along with the storage $\left(\mathrm{G}^{\prime}\right)$ and loss modulus $\left(\mathrm{G}^{\prime \prime}\right)$ at constant frequency and percent strain. The storage modulus $\left(G^{\prime}\right)$ showed the dominant contribution to $G^{*}$, since $G^{\prime}$ value was higher than the $\mathrm{G}^{\prime \prime}$ in all conduits, verifying that the conduits indeed displayed elastic behavior. NF conduits showed the highest $G^{*}$ values indicating a stiffer nature than that of MP and LL conduits with sequentially smaller $G^{*}$ values. This result simply illustrated that although all of the conduits displayed elastic behavior, their relative stiffness changed with the microstructure. The stiffest conduit with the highest $\mathrm{G}^{*}$ value (NF) had the smallest pore size and swelling capacity (Fig. 2A and B), which is in accordance with findings in the literature [87]. All three conduits showed $\tan \delta$ values between 0 and 1, exhibiting solid-like behavior at physiological temperatures. Overall, these conduits maintained their integrity 

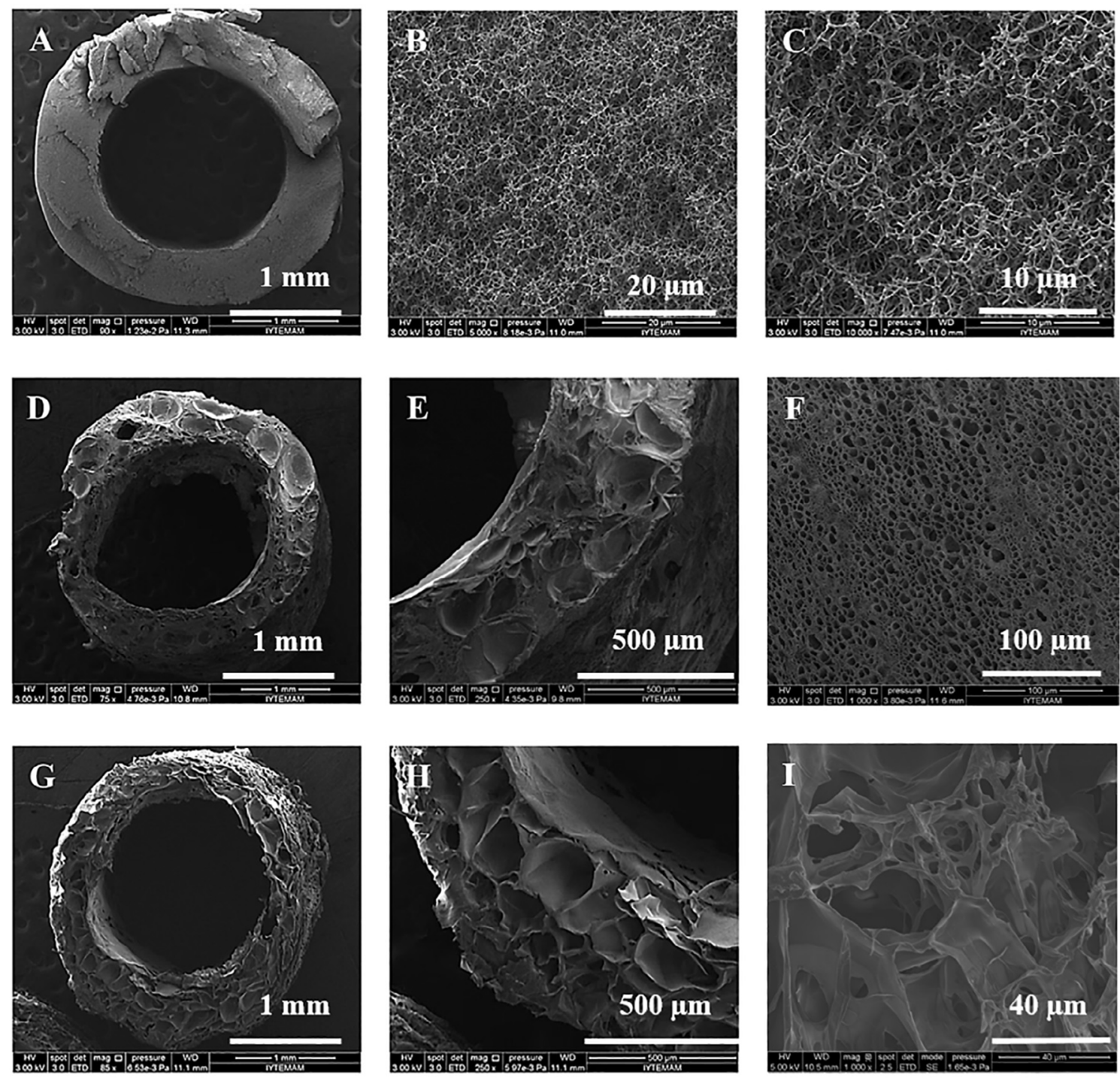

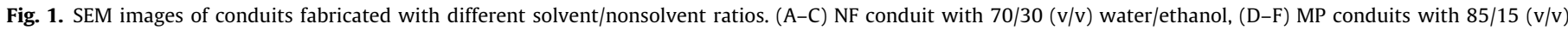
water/ethanol and (G-I) LL conduits with $100 \%$ water. Images C, F and I represent the inner lumen pore structure of each conduit.

(A)

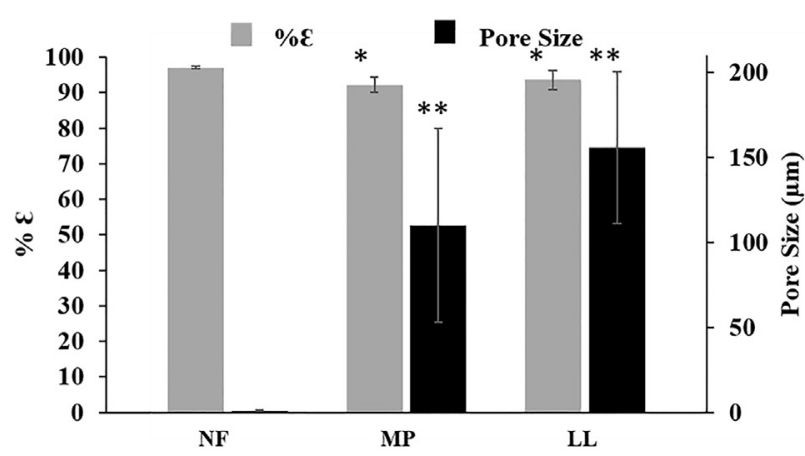

(B)

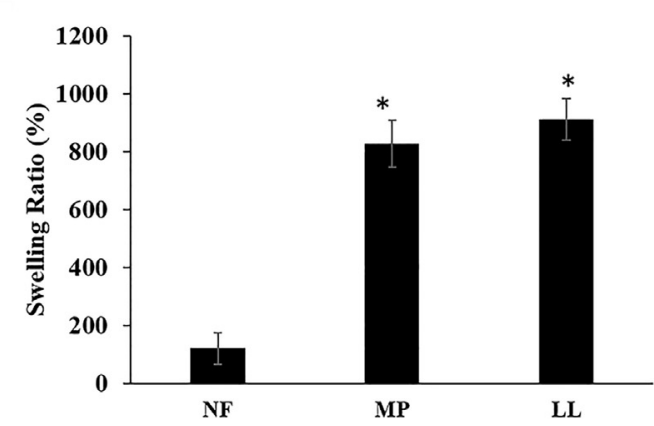

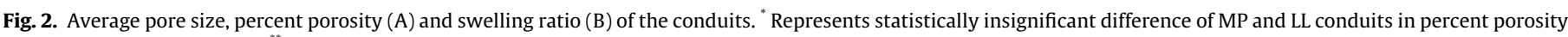

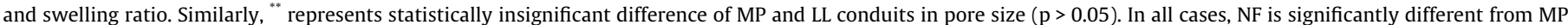
and LL conduits.

under physiological conditions while proposing the possibility of tuning their properties (pore size, swelling ratio and stiffness/elasticity) to control the growth and function of the cells. Moreover, the conduits did not show a significant reduction in the storage and loss modulus after incubation in cell culture media for 15 days (Fig. 2.S.). Apart from these properties, the elastic behavior along 
(A)

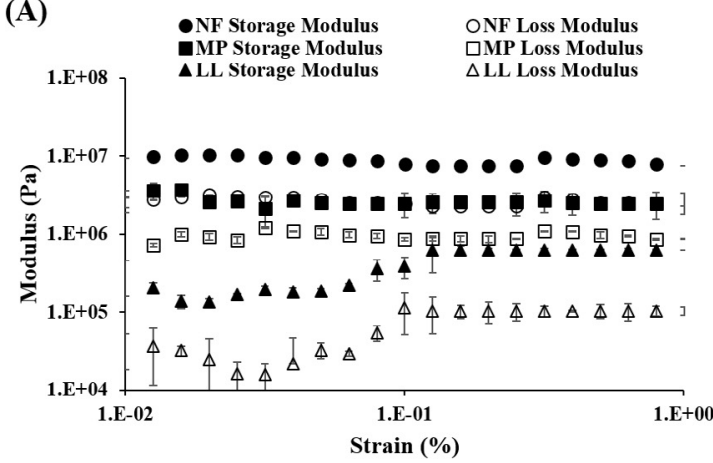

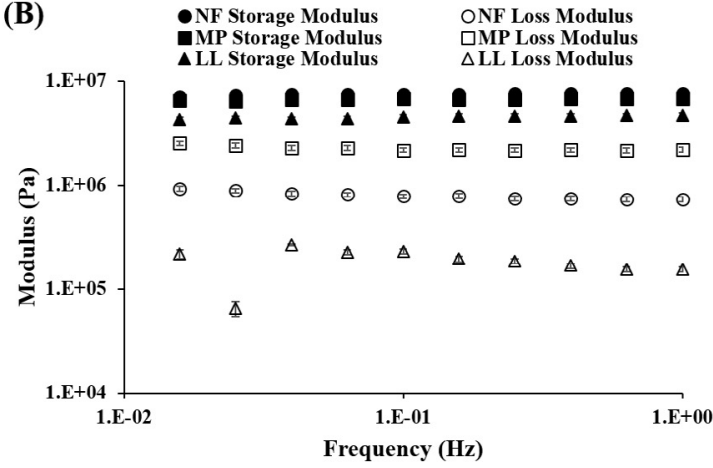

Fig. 3. Evolution of the storage $\left(G^{\prime}\right)$ and loss $\left(G^{\prime \prime}\right)$ moduli, as a function of $(A)$ percent strain and (B) frequency for prepared conduits. ( $\left.p<0.05\right)$.

Table 2

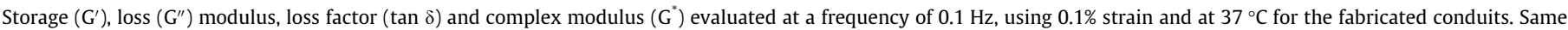
letters represent statistically insignificant differences $(\mathrm{p}>0.05)$.

\begin{tabular}{|c|c|c|c|c|}
\hline & $\mathrm{G}^{\prime} \times 10^{6}(\mathrm{~Pa})$ & $\mathrm{G}^{\prime \prime} \times 10^{6}(\mathrm{~Pa})$ & $\tan \delta$ & $\mathrm{G}^{*} \times 10^{6}(\mathrm{~Pa})$ \\
\hline NF & $7.80 \pm 0.19$ & $1.86 \pm 0.98^{\mathrm{b}}$ & $0.24 \pm 0.12^{\mathrm{c}}$ & $8.06 \pm 0.38$ \\
\hline MP & $3.89 \pm 2.50^{\mathrm{a}}$ & $1.30 \pm 0.83^{\mathrm{b}}$ & $0.33 \pm 0.05^{c}$ & $4.10 \pm 2.6^{\mathrm{d}}$ \\
\hline LL & $0.38 \pm 0.12^{\mathrm{a}}$ & $0.32 \pm 0.05$ & $0.22 \pm 0.15^{c}$ & $0.40 \pm 0.13^{\mathrm{d}}$ \\
\hline
\end{tabular}

a Represents the $\mathrm{G}^{\prime}$ values that are not significantly different for MP and LL conduits but significantly higher for NF conduits.

b Represents the $G^{\prime \prime}$ values that are not significantly different for NF and MP conduits but significantly lower for LL conduits.

c Represents that $\tan \delta$ values that do not change significantly with respect to conduit type.

d Represents the $\mathrm{G}^{*}$ values that are not significantly different for MP and LL conduits but are significantly higher for NF conduits.

with the stiffness characteristics, transparent nature and expansion upon hydration, provides these conduits easy handling during the surgical procedures $[88,89]$.

\subsection{Morphology, proliferation, spreading and viability of MSCs in different conduits}

It is well known that there are differences in morphology and behavior when cells are cultured in 2D versus 3D matrices [65]. Considering the dynamic nature of the ECM microenvironment, cell culture experiments carried out in 2D are limited in their ability to investigate and define natural cellular features such as morphology, proliferation, spreading, differentiation, activation of signaling pathways and ultimately cell behavior [65]. Therefore, the additional dimensionality that the cells experience in $3 \mathrm{D}$ is a powerful approach to control cell features and behavior in artificial matrices mimicking the ECM. The tMSCs-2D (MSCs previously transdifferentiated into SC like phenotype in a T75 flask) and uMSCs (undifferentiated MSCs) were grown on conduits with different 3D microstructures and on 2D TCPS plates to observe cellular behavior in different matrices (Fig. 4.). At the end of day 1 and 5 , the cells in MP, LL conduits and 2D TCPS plates were stained and imaged using fluorescence microscopy, whereas the cells in NF conduits were visualized under SEM due to their opaque nature preventing the imaging with fluorescence microscopy. It was observed that both tMSCs-2D and uMSCs initially attached and proliferated on the conduits and 2D TCPS plates at the end of the first day. Although the initial cell plating density was the same for all substrates $\left(1 \times 10^{4}\right.$ cell $\left./ \mathrm{cm}^{2}\right)$ and cell types, cells showed a higher attachment tendency towards the 2D TCPS plates, showing more cells compared to their 3D gelatin conduit counterparts at the first day (Fig. 4.). However, at the end of 5 days, the number of cells on the 2D TCPS plates were considerably lower than that on the 3D MP and LL conduits for both tMSCs-2D and uMSCs, while the number of cells on NF conduits were similar to the 2D TCPS plates, indicating a difference in substrate dependent cell proliferation. In addition, both tMSCs-2D and uMSCs in MP and LL conduits exhibited a higher degree of cell spreading and the formation of interconnected cellular networks within the 3D conduit structure at the end of 5 days as compared to NF conduits and 2D TCPS plates. This was likely due to the higher complex moduli $\left(G^{*}\right)$, and thus the higher stiffness and smaller pore sizes (Figs. 2 and 3 and Table 2) of the NF conduits and 2D TCPS plates, resulting in a denser matrix surrounding the cells. Large pores can allow effective diffusion and absorption of cells and cell culture media. Therefore conduits with larger pores (such as MP or LL) can retain more cells and culture medium in their microstructure as well as allowing more space to grow, than conduits with smaller pores, such as NP conduits [74]. Consequently, the cells were observed to slow their proliferation which may likely be due to limitations associated with space and greater cell-cell contact inhibition in NF conduits and 2D TCPS plates [90]. This is also in accordance with some recent studies involving other cell types, which reported hydrogel stiffness dependent proliferation and spreading of fibroblast and muscle cells [90-92]. For instance, Bott [90] noted the decreasing proliferation and spreading of fibroblast cells with increasing material stiffness in the MMP-degradable PEG hydrogels suggesting that cells need to remodel their pericellular and extracellular environment in order to effectively spread and proliferate. The MP and LL conduits prepared in this study with relatively smaller complex moduli $\left(G^{*}\right)$ values and significantly larger pores compared to NF conduits provided an available microenvironment for the cells to spread and proliferate resulting in higher number of cells at the end of 5 days. The results suggest that cell proliferation, cell spreading and their ability to form interconnected cellular 3D networks were enhanced in the conduits with low $\mathrm{G}^{*}$ values and large pore sizes (MP and LL conduits) consistent with the literature [80,93-95]. The tMSCs-2D possessed heterogeneous morphologies, bearing multipolar, spindle as well as fibroblastic shapes and showed better proliferation while uMSCs had a round and fibroblastic-like morphology with relatively limited proliferation in the conduits. Although the higher proliferation rate of tMSCs2D than uMSCs was contradictory to our previous findings [19] on $2 \mathrm{D}$ cell culture plates, this difference may be attributed to the 

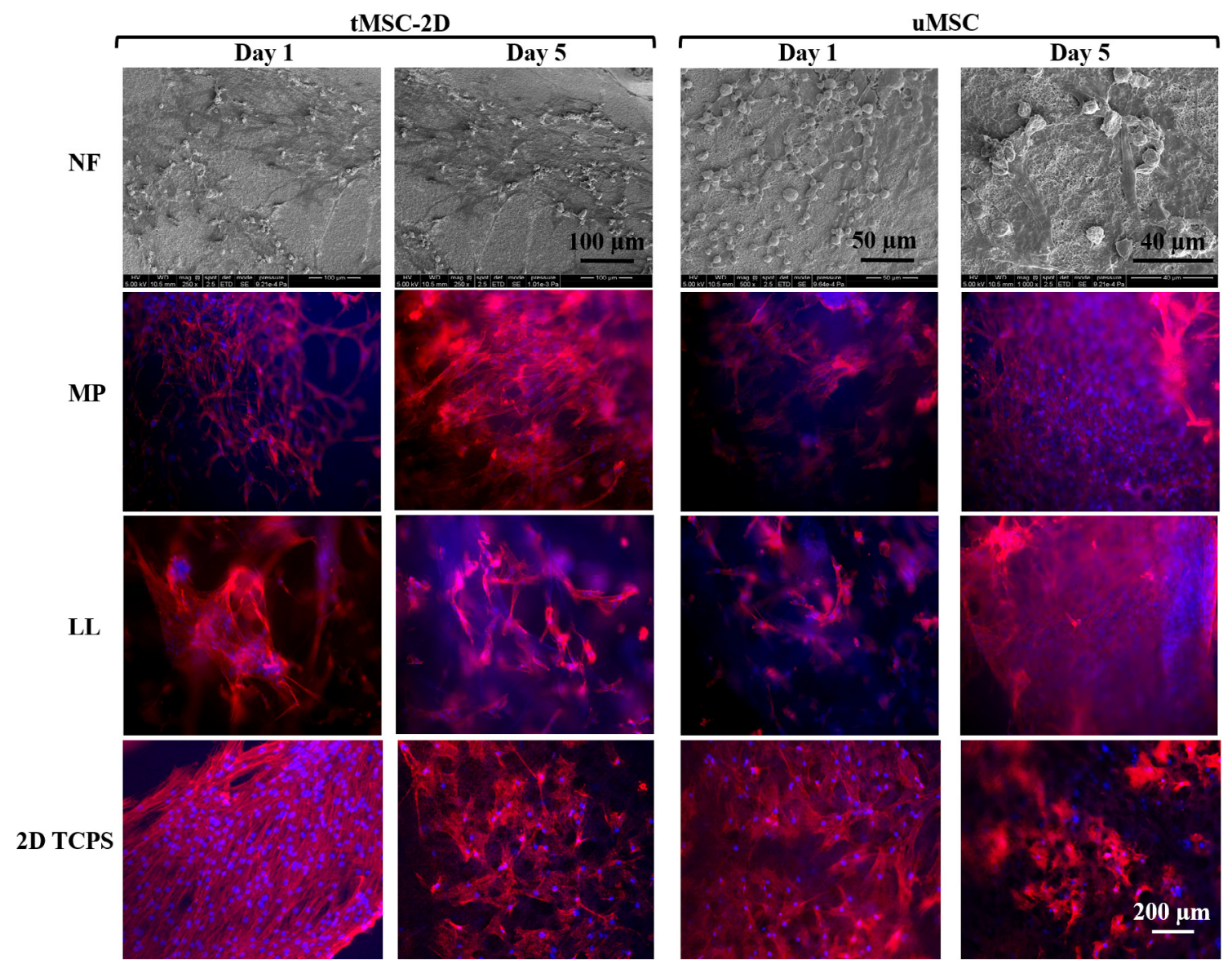

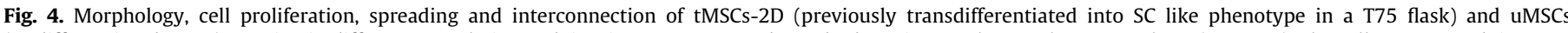

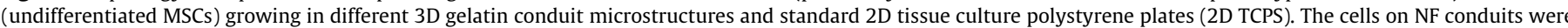

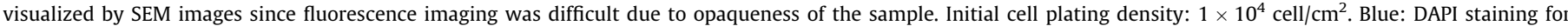
nucleus and Red: Rhodamine Phalloidin staining for actin filaments.

effect of the 3D conduit microstructure and mechanical properties enhancing the spreading and proliferation of tMSCs-2D. In accordance with our findings, previously published data also reported increased cell proliferation and spreading in 3D matrices with lowered material stiffness $[65,66,80,90]$. Overall the results show that the conduits prepared in this study with adjustable microstructure, pore size and stiffness are promising materials mimicking the ECM microenvironment for the MSCs.

The number of viable cells after 15 days of incubation in 3D conduits and 2D TCPS plates were also determined for both tMSCs-2D and uMSCs (Fig. 5.). Both cell types showed the least number of viable cells on NF conduits possessing the stiffest nature with highest $G^{*}$ value, while MP and LL conduits with relatively less stiffness and larger pores provided a more conducive environment for cell growth and survival. Therefore, the number of cells within 3D MP and LL conduits almost doubled in 15 days. These results are in accordance with the observations represented in Fig. 4.

\subsection{Transdifferentiation of MSCs into SC like phenotypes in different conduits}

The structural and mechanical properties of scaffolds affect the differentiation characteristics of the MSCs as they significantly alter cell morphology, spreading and proliferation. To examine the direct effect of microstructural and mechanical scaffold properties on transdifferentiation behavior, the undifferentiated MSCs (uMSCs) were seeded and transdifferentiated on 3D gelatin con-

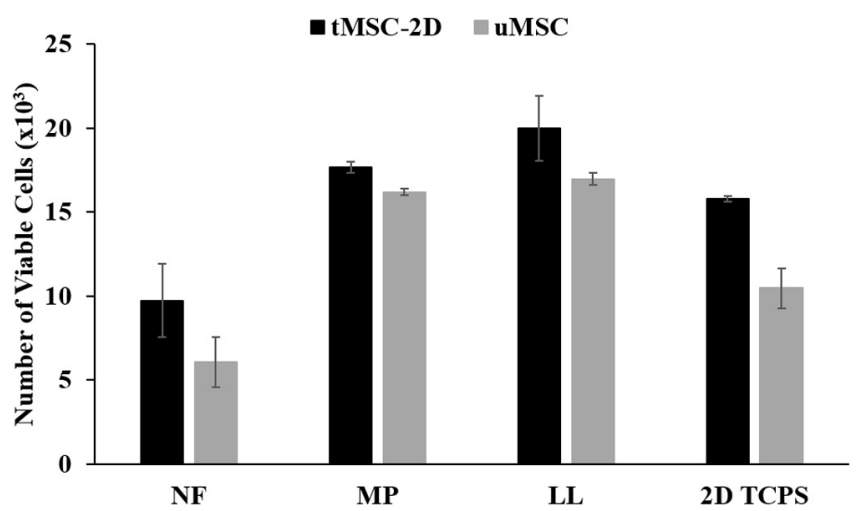

Fig. 5. Cell viability of tMSCs-2D (previously transdifferentiated into SC like phenotype in a T75 flask) and uMSCs (undifferentiated MSCs) seeded in different 3D gelatin conduits at the end of 15 days incubation. Initial cell density: $1 \times 10^{4}$ cell/ $\mathrm{cm}^{2}(\mathrm{p}<0.05)$.

duits and 2D TCPS plates (as controls). The tMSCs grown and transdifferentiated in 3D conduits were characterized and compared with the cells transdifferentiated on 2D TCPS plates and control uMSCs by immunostaining using glial markers such as $\alpha$-S100, $\alpha$-S100 $\beta$ and $\alpha$-p75 used to identify SCs (Fig. 6) [96]. A common glial marker, GFAP, was not selected for the tests based on our previous data indicating no detectable GFAP expression in tMSCs [19]. As before, the transdifferentiation of uMSCs within NF conduits 

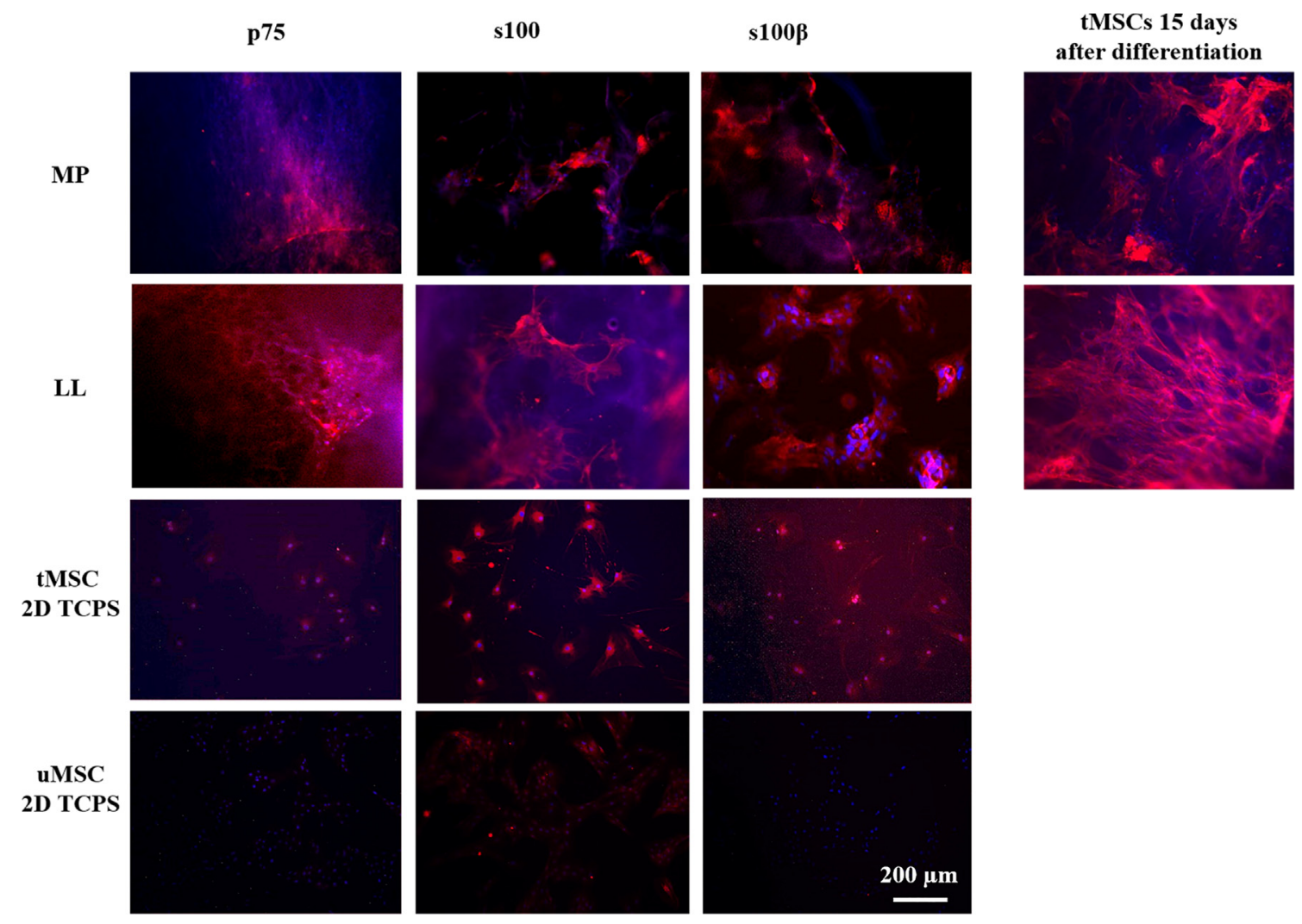

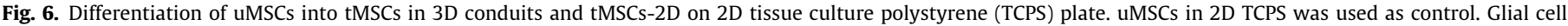

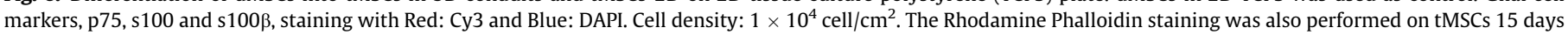
after transdifferentiation in 3D conduits.

could not be visualized under fluorescence microscopy due to the opaque nature of the conduit. The visualization and degree of immunostaining of selected markers across MP, LL conduits and 2D TCPS plate controls were presented in Fig. 6 for tMSCs, tMSCs-2D and uMSCs. The results for 2D TCPS plate substrates shown in Fig. 6 revealed that anti-S100 $\beta$ showed no detectable immunolabeling of the uMSCs while anti-p75 antibodies immunolabeled very few uMSCs compared to tMSCs-2D on 2D TCPS plates. The reason for p-75 immunostaining of uMSCs was due to occasional nuclear staining while it was cytoplasmic for transdifferentiated MSCs [19]. Because of this reason, the cytoplasmic anti-p75 staining of cells were taken into account [19]. In addition, although not very effective as in the case of transdifferentiated MSCs, antiS100 immunolabeling was also observed for the uMSCs on 2D TCPS plates. Compared to the uMSCs, the tMSCs-2D on 2D TCPS plates showed a significant degree of immunostaining of SC markers with more than $85 \%$ of cell staining indicating successful transdifferentiation (Fig. 6). The cells transdifferentiated in MP and LL conduits also showed a high degree of immunolabeling indicating the suitability of the conduits for transdifferentiation as well. More than $85 \%$ of the cells in LL conduits showed efficient labeling for all selected markers. The immunolabeling of the cells in MP conduits were $\sim 65 \%$ for $\mathrm{p} 75, \sim 75 \%$ for $\mathrm{S} 100$ and $\sim 85 \%$ for $\mathrm{S} 100 \beta$ markers. This difference could be attributed to the microstructural and mechanical differences between MP and LL conduits, with MP having slightly smaller pore size and stiffer nature compared to LL conduits, (Figs. 2, 3 and Table 2) limiting the differentiation of the cells. Although, the degree of immunolabeling is slightly lower in MP conduits than that of 2D TCPS plate controls, our overall results of differentiating uMSCs into tMSCs directly in 3D gelatin conduits are competitive with our previous reports indicating the MSC transdifferentiation in T75 flasks [19]. In addition, our reported immunolabeling percentages (85\% of the cells in LL for all markers and $\sim 65 \%$ for $\mathrm{p} 75, \sim 75 \%$ for $\mathrm{S} 100$ and $\sim 85 \%$ for $\mathrm{S} 100 \beta$ markers in $\mathrm{MP}$ ) are highly consistent with the values reported in the literature despite the different conditions. For instance, Ladak [97] quantified MSC marker expression as 51\% GFAP, 47\% S100 and 45\% NGFR upon the MSC differentiation into Schwann-like cells in T-75 flasks using the modified protocol from Dezawa [27], demonstrating heterogeneous differentiation of approximately $50 \%$ of cells present in culture which is considerably lower than what we observed in 3D conduits [97]. Following the transdifferentiation of uMSCs in the MP and LL conduits into tMSCs, the cells were kept in their respective environment for another 15 days and it was observed that uMSCs directly transdifferentiated in MP and LL conduits continued to proliferate and spread within this period (Fig. 6). Overall our results showed that the $3 \mathrm{D}$ gelatin conduits with different microstructures and mechanical properties not only successfully mimic the ECM for proliferation and spreading, but also provide a convenient environment for cell transdifferentiation.

\subsection{Paracrine activity of tMSCs and uMSCs grown in different $3 D$ conduits}

Schwann cells are capable of secreting certain neurotrophic factors, such as NGF, GDNF and BDNF, during injury leading to formation of diffusion gradients and activation of intracellular signal transduction pathways that enhance regenerating axon growth and neuron survival $[17,98,99]$. The differentiated MSCs possessing SC-like phenotype were also capable of secreting neurotrophic factors and the degree of secretion changes depending on the microstructural and mechanical properties of the scaffold. 
Therefore, the degree of cell secreted neurotrophic factors can be considered another measure of cell differentiation. As such, ELISAs were conducted to determine the amount of NGF, GDNF and BDNF, secreted from the tMSCs differentiated in NF, MP and LL 3D gelatin conduits as well as tMSCs-2D in the 2D TCPS control plates (Fig. 7). The secretion of NGF and GDNF in all types of conduits and 2D TCPS plates were higher in tMSCs than the uMSCs as expected whereas BDNF release was not detected from either of the cell types. The NGF release from uMSCs in different conduits was not found to be significantly different (Fig. 7A) on the other hand, the NGF, secreted from tMSCs, varied depending on the conduit microstructure. The tMSCs differentiated in LL conduits showed the highest NGF secretion $(\sim 2.5 \mathrm{pg} / \mathrm{mL}$ per cell $)$ whereas those in NF showed the lowest NGF secretion $(\sim 0.8 \mathrm{pg} / \mathrm{mL}$ per cell). The highest NGF release in the LL conduits may be attributed to its microstructure with favorable porosity, pore size and elasticity (Figs. 1-3 and Table 2) enabling a higher degree of transdifferentiation and number of viable cells (Figs. 4-6), significantly enhancing NGF secretion capability. Although the porosity, pore size and swelling ratio of MP and LL conduits were found to be close to each other, the NGF secretion capacity of the tMSCs in MP conduits were significantly smaller than that of LL conduits (Fig. 7A). This may be due to the slightly stiffer nature of MP conduits (Table 2) which actually lowered cell viability and degree of transdifferentiation (Figs. 5 and 6). The amount of NGF released from tMSCs in NF conduits was even lower than the 2D TCPS plates, which was due to the inefficient differentiation and fewer number of cells present in the NF conduit as shown in Figs. 4 and 5. The stiff nature, small pore size and low swelling ratio of NF conduits (Figs. 1-3) prevented cellular attachment and differentiation leading to insignificant paracrine activity. The overall GDNF release from the tMSCs was lower than the NGF release regardless of the conduit type (Fig. 7B). The tMSCs in MP and LL conduits secreted significantly higher amount of GDNF than that from NF conduits and 2D TCPS plates. In all cases, the GDNF or NGF amount released from the uMSCs were significantly lower compared to the amounts secreted from tMSCs (Fig. 7B.).

In order to investigate the biological activity of the released NGF and GDNF from the tMSCs differentiated in various 3D conduits and 2D TCPS plates, a co-culture experiment with PC12 cells was conducted and the results of neurite extension in PC12 cells triggered by the secreted NGF and GDNF were represented in Table 3 and Figure S.3. in Supplementary Information. The tMSCs differentiated in LL conduits triggered the greatest neurite extension in PC12 cells, which was followed by MP conduits, 2D TCPS plates and NF conduits (Table 3 ). This trend was consistent with the neurotrophic factor secreting capacity of the tMSC-differentiated conduits illustrated in Fig. 7. We did not observe any significant enhancement in neurite extension of the PC12 cells in contact with the uMSCs in conduits regardless of the conduit type (Table 3).

\section{Discussion}

Cell-based nerve regeneration therapies (including autologous or allogeneic cells) are being investigated as important strategies for the treatment of large peripheral nerve injuries. Autologous cell-based treatment has been considered as a promising approach for the repair of peripheral nerve injuries in the clinic, particularly for chronic injuries, because they pose little risk of immunological rejection. However, it is difficult to obtain sufficient quantities of healthy cells with high activity from every patient. Furthermore, cell extraction is time-consuming, making it difficult to use them promptly to treat acute diseases [41,100-102]. In contrast, allogeneic cell-based treatment is readily available and can be administered immediately to treat acute injuries. In addition, obtaining allogeneic cells from young healthy donors is a reasonable approach with advantages of quality assurance, reduced time and cost. However, the allogeneic cell-based treatment has been reported to possess the risk of immunological rejection $[41,100-$ 102 ]. Regardless of the pros and cons of each treatment approach, an appropriate conduit system is required for efficient cell transplantation and nerve regeneration. Therefore, in this study, gelatin-based 3D porous conduits with different microstructures and mechanical properties were fabricated using combined molding and TIPS techniques. These conduits can be used in the transplantation of both autologous and allogeneic cells to treat acute or chronic injuries. The ease of TIPS technique in the preparation of different microstructures as opposed to difficulties in electrospinning and self-assembly techniques $[67,68]$ to achieve 3D structures and its cost effectiveness makes our strategy favorable and a promising alternative for 3D conduit production intended for neural tissue engineering.

Significant data regarding differentiation and behavior of stem cells from different sources have been obtained from cells cultured on regular 2D tissue culture plate surfaces [103]. However, lack of one dimension in 2D substrates biases the true differentiation behavior or potential of stem cells pointing out the need for $3 \mathrm{D}$ scaffolds mimicking the complex microenvironment to achieve more reliable information $[65,95]$. Therefore, to address this issue we have successfully created 3D structures in gelatin conduits in order to examine cell differentiation. Most of the studies in the literature used MSCs that had already been transdifferentiated in regular 2D cell culture environments for transplantation purposes $[16,17,20,21]$, whereas, in this study, the transdifferentiation of MSCs was performed directly within the developed 3D gelatin conduits with different microstructures and mechanical properties.
(A)

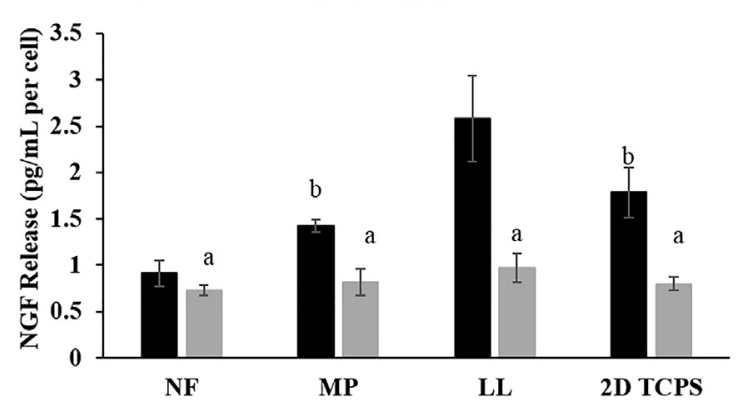

(B)

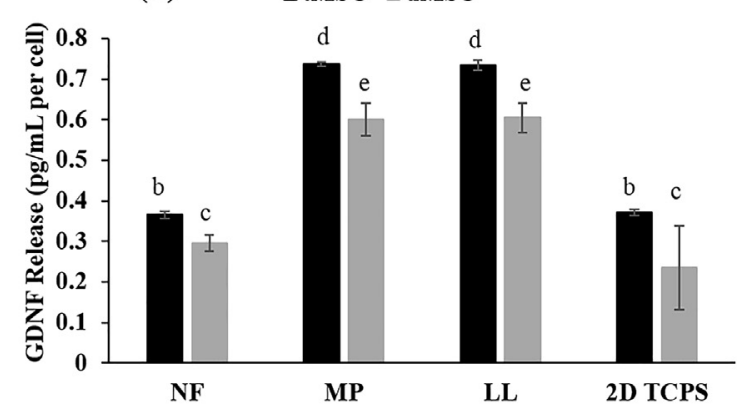

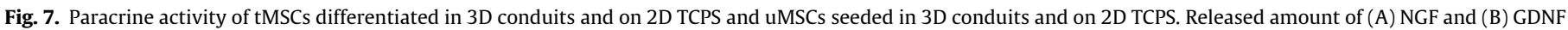

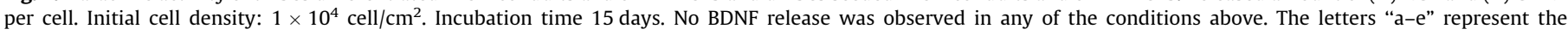
insignificant difference $(p>0.05)$. 
Table 3

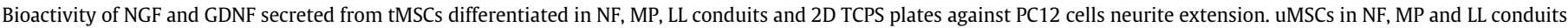
and 2D TCPS plate were used as control. PC12 cells density: $1 \times 10^{4}$ cell $/ \mathrm{cm}^{2}$. tMSCs cell density in conduits: $1 \times 10^{4}$ cell/cm ${ }^{2}$. Incubation time: $72 \mathrm{~h}$. ( $\mathrm{p}<0.05$ ).

\begin{tabular}{|c|c|c|c|c|}
\hline \multirow[t]{2}{*}{ Cell Type } & \multicolumn{4}{|c|}{ Neurite Length per Cell $(\mu \mathrm{m})$} \\
\hline & NF & MP & LL & 2D TCPS \\
\hline tMSC & $2.00 \pm 0.58$ & $4.40 \pm 0.25$ & $9.80 \pm 0.67$ & $3.90 \pm 0.47$ \\
\hline uMSC & $1.50 \pm 0.45$ & $2.30 \pm 0.58$ & $1.70 \pm 0.80$ & $1.60 \pm 0.93$ \\
\hline
\end{tabular}

This strategy has not only provided significant information about the differentiation as well as morphology, proliferation and spreading behavior of the cells in different 3D environments, but also led to the reduction in differentiation steps, cost, effort and time [85,104-106], while enhancing the bioactivity of the transplanted cells in promoting neurite outgrowth. The studies investigating the effect of various conduit structure and mechanical properties on differentiation of MSC from different sources (adipose tissue, placenta, umbilical cord blood etc.) were mostly focused on the osteogenic differentiation [86,107-109], however, to the best of our knowledge there is no other study reporting the influence of these properties on transdifferentiation of bone marrow-derived MSCs into SC-like phenotypes.

Our results indicated that the change in solvent/non-solvent ratio controlled the structural and mechanical properties of the developed 3D gelatin conduits (Figs. 1-3 and Table 2) which in turn determined cellular behaviors such as morphology, proliferation, spreading and differentiation (Figs. 4-7 and Table 3). It was previously reported that the elasticity of human tissues varies depending on the site (brain $(E=0.1-1 \mathrm{kPa})$, muscle $(E=8-$ $17 \mathrm{kPa})$, skin $\left(\mathrm{E}=10-10^{3} \mathrm{kPa}\right)$ and bone $\left.\left(\mathrm{E}=10^{6}-10^{7} \mathrm{kPa}\right)\right)[110]$. Our values of complex modulus $\left(\mathrm{G}^{*}\right)$ were found to vary between $0.27 \times 10^{3}$ and $8.44 \times 10^{3} \mathrm{kPa}$ depending on the conduit microstructure (Table 2), which showed that the fabricated conduits were in high stiffness range. According to previous reports on 2D substrates, high material stiffness promoted cell attachment [111], proliferation [90], spreading [90,112], morphology [113], and migration [114]. Although NF conduits had high stiffness and porosity, the presence of small pores in 3D structure decreased the available space and prevented the attachment and proliferation of cells. On the other hand, the MP and LL conduits, exhibiting softer nature with larger pore sizes compared to NF conduits, both provided required stiffness and a favorable microenvironment for substantial cellular attachment, proliferation and spreading. In addition, the 3D structure of these conduits can contribute to the recruitment of proteins to adhesion sites which may also facilitate proliferation and spreading [115-117]. Consequently, the proliferation and spreading capacity of the MSCs in the heterogeneous and anisotropic 3D structures of our conduits contributed to neural differentiation.

Previous studies have shown that the matrix stiffness regulates the differentiation of MSCs into specific lineages. For instance, Engler [110] observed neurogenic differentiation on soft substrates with elasticities ranging between 0.1 and $2 \mathrm{kPa}$. Lanniel [118] found that MSCs on soft hydrogels displaying $6.5 \mathrm{kPa}$ elasticity expressed neuronal morphologies and neural markers, whereas those cells growing on stiffer matrices $(41 \mathrm{kPa})$ expressed osteogenic markers. Although our conduits have a stiff nature (ranging between $0.27 \times 10^{6}$ and $8.44 \times 10^{6} \mathrm{~Pa}$ ), our results indicated that they were capable of supporting neurogenic differentiation. This could be due to the large pores within the 3D structure enabling efficient changes in cell proliferation, spreading and morphology leading to differentiation. Indeed, the SC like differentiation of MSCs on our conduits was expected since these cells had already been successfully transdifferentiated into SC-like phenotypes on regular 2D TCPS plates $[16,17,19,27]$ with significantly stiffer nature than our conduits. Neuronal differentiation potential in stiff
3D conduit structures was also reported by previous studies $[56,65,119]$. In addition to the matrix stiffness, the intrinsic mechanical properties of MSCs may also contribute to their differentiation ability into SC-like phenotype [80]. Stiff single cells, such as bone marrow derived MSC with the elastic moduli of $\sim 3.2 \mathrm{kPa}$ [120], have been effectively differentiated into various lineages in stiff conduits as in our case. Although it has been demonstrated that matrix elasticity affects MSC differentiation, the mechanism has not yet been clearly delineated. It was previously reported that matrix stiffness may trigger multiple signaling pathways through mechanotransduction and mechanosensors including integrins [121], ion channels [122], cell adhesion [123], actin cytoskeleton [124], and surface receptors [125]. Among those pathways, we anticipated that differentiation of MSCs was modulated by blocking of the BMP/Smad signaling pathway, which promotes integrin internalization, enhancing bone morphogenetic protein receptors (BMPR) endocytosis and neuronal gene expression [62,126]. We reported significant neurotrophic factor release from the MSCs differentiated in the fabricated 3D conduits (ranging between 1 and $3 \mathrm{pg} / \mathrm{mL}$ per cell of NGF and 0.35 to $0.7 \mathrm{pg} / \mathrm{mL}$ per cell of GDNF) and their biological activity against PC12 cells (neurite outgrowth ranging from 2 to $10 \mu \mathrm{m}$ per cell). Brohlin [127] reported $\sim 0.01 \mathrm{pg} / \mathrm{mL}$ per cell of BDNF release along with relatively smaller amounts of NGF and GDNF upon bone marrow-derived MSCs differentiation on regular 2D TCPS plates using very similar transdifferentiation protocol. Their results indicated that differentiation of MSCs resulted in upregulation of BDNF ( $\sim 0.01 \mathrm{pg} / \mathrm{mL}$ per cell), elevating its secretion, while the levels of NGF and GDNF remained same and lower than BDNF [127]. Compared to this study, although we did not detect any significant BDNF secretion, our NGF and GDNF secretion capacity per cell, particularly in MP and LL conduits was significantly higher illustrating the advantage of 3D structure with appropriate stiffness and pore size for efficient transdifferentiation. The neurotrophic factors released from tMSCs in $3 \mathrm{D}$ conduits (with cell density of $1 \times 10^{4}$ cell $/ \mathrm{cm}^{2}$ ) showed significant bioactivity against PC12 cells by inducing neurite extension of $2-10 \mu \mathrm{m} /$ cell (Table 3 ). Other studies conducted with 2D TCPS plates have shown similar bioactivity against dorsal root ganglia and spinal motor neurons, causing neurite extensions of $\sim 0.1 \mu \mathrm{m} /$ cell with 75,000 tMSCs/mL $[16,127]$ and neurite extension of $\sim 2 \mu \mathrm{m} /$ cell with $5000 \mathrm{MSCs} / \mathrm{cm}^{2}$ [128], respectively. Despite the differences in initial tMSC seeding density and target cells, our results were found comparable with the findings in the literature in terms of biological and paracrine activity indicating the promoting effect of 3D gelatin conduits (especially MP and $\mathrm{LL}$ ) and their variable microstructure and mechanical properties.

\section{Conclusion}

3D gelatin conduits with different microstructures were successfully fabricated with a combined molding and TIPS technique through changing solvent/non-solvent ratios. This strategy offers an easy and cost effective way to fabricate gelatin-based 3D conduits with various microstructures providing advantages over currently used electrospinning and self-assembly techniques. The microstructural (pore size ranging between 5 and $150 \mu \mathrm{m}$ ) and 
mechanical properties ( $\mathrm{G}^{*}$ ranging between $0.27 \times 10^{6}$ and $8.44 \times 10^{6} \mathrm{~Pa}$ ) of the conduits significantly influenced the cellular behavior and differentiation. The stiff nature of 3D conduits, along with the right pore size and microstructure, enhanced MSC attachment, proliferation, spreading with high numbers of viable cells and differentiation. In contrast to some reports indicating that softer matrices promote neural differentiation while stiffer ones enhance osteogenic differentiation, our results emphasized that highly porous, large pore sized stiff matrices were also capable of supporting MSC differentiation into SC-like phenotypes. The direct transdifferentiation of MSCs within the 3D conduit matrices supported neurotrophic factor secretion, showing significant bioactivity on PC12 cells neurite outgrowth. Both neurotrophic factor secretion capacity and bioactivity of the tMSCs in 3D gelatin conduits were found to be significantly higher than that of their 2D and 3D counterparts. Overall, it can be concluded that 3D conduits prepared in this study showed promising results for neural regeneration applications. In addition, the proper elastic behavior of the conduits coupled with the stiffness characteristics, transparent nature and expansion upon hydration enable easy handling for the surgical procedures. In conclusion, the in vivo performance of these conduits should be tested.

\section{Acknowledgments}

The authors would like to acknowledge the US Army Medical Research and Materiel Command under contract W81XWH-111-0700 and the Stem Cell Biology Fund for funding this work. We are also grateful to the Stanley Endowed Chair for providing additional funds in support of this work. We also acknowledge Izmir Institute of Technology Material Research and Application Center for technical support.

\section{Appendix A. Supplementary data}

Supplementary data associated with this article can be found, in the online version, at http://dx.doi.org/10.1016/j.actbio.2017.02. 018.

\section{References}

[1] R.P. Bunge, The role of the Schwann cell in trophic support and regeneration, J. Neurol. 242 (1 Suppl 1) (1994) S19-S21.

[2] C. Ide, Peripheral nerve regeneration, Neurosci. Res. 25 (2) (1996) 101-121.

[3] N.K. Mahanthappa, E.S. Anton, W.D. Matthew, Glial growth factor 2, a soluble neuregulin, directly increases Schwann cell motility and indirectly promotes neurite outgrowth, J. Neurosci. 16 (15) (1996) 4673-4683.

[4] G. Terenghi, Peripheral nerve regeneration and neurotrophic factors, J. Anat. 194 (Pt 1) (1999) 1-14.

[5] M. Wiberg, G. Terenghi, Will it be possible to produce peripheral nerves?, Surg Technol. Int. 11 (2003) 303-310.

[6] K.R. Jessen, R. Mirsky, Schwann cells and their precursors emerge as major regulators of nerve development, Trends Neurosci. 22 (9) (1999) 402-410.

[7] E.J. Sandquist, M. Uz, A.D. Sharma, B.B. Patel, S.K. Mallapragada, D.S. Sakaguchi, Stem cells, bioengineering, and 3-D scaffolds for nervous system repair and regeneration, in: G.L. Zhang, L.D. Kaplan (Eds.), Neural Engineering: From Advanced Biomaterials to 3D Fabrication Techniques, Springer International Publishing, 2016, pp. 25-81.

[8] S.K. Mallapragada, T.M. Brenza, J.M. McMillan, B. Narasimhan, D.S. Sakaguchi, A.D. Sharma, S. Zbarska, H.E. Gendelman, Enabling nanomaterial, nanofabrication and cellular technologies for nanoneuromedicines, Nanomedicine 11 (3) (2015) 715-729.

[9] M.E. Marti, A.D. Sharma, D.S. Sakaguchi, S.K. Mallapragada, 10 Nanomaterials for neural tissue engineering, in: A.K. Gaharwar, S. Sant, M.J. Hancock, S.A. Hacking (Eds.), Nanomaterials in Tissue Engineering, Woodhead Publishing, 2013, pp. 275-301.

[10] V. Guenard, N. Kleitman, T.K. Morrissey, R.P. Bunge, P. Aebischer, Syngeneic Schwann cells derived from adult nerves seeded in semipermeable guidance channels enhance peripheral nerve regeneration, J. Neurosci. 12 (9) (1992) 3310-3320.

[11] A. Mosahebi, B. Woodward, M. Wiberg, R. Martin, G. Terenghi, Retroviral labeling of Schwann cells: in vitro characterization and in vivo transplantation to improve peripheral nerve regeneration, Glia 34 (1) (2001) 8-17.

[12] F.J. Rodriguez, E. Verdu, D. Ceballos, X. Navarro, Nerve guides seeded with autologous schwann cells improve nerve regeneration, Exp. Neurol. 161 (2) (2000) 571-584.

[13] J. Caddick, P.J. Kingham, N.J. Gardiner, M. Wiberg, G. Terenghi, Phenotypic and functional characteristics of mesenchymal stem cells differentiated along a Schwann cell lineage, Glia 54 (8) (2006) 840-849.

[14] A. Mosahebi, P. Fuller, M. Wiberg, G. Terenghi, Effect of allogeneic Schwann cell transplantation on peripheral nerve regeneration, Exp. Neurol. 173 (2) (2002) 213-223.

[15] M. Tohill, C. Mantovani, M. Wiberg, G. Terenghi, Rat bone marrow mesenchymal stem cells express glial markers and stimulate nerve regeneration, Neurosci. Lett. 362 (3) (2004) 200-203.

[16] M. Brohlin, D. Mahay, L.N. Novikov, G. Terenghi, M. Wiberg, S.G. Shawcross, L. N. Novikova, Characterisation of human mesenchymal stem cells following differentiation into Schwann cell-like cells, Neurosci. Res. 64 (1) (2009) 4149.

[17] G. Keilhoff, A. Goihl, F. Stang, G. Wolf, H. Fansa, Peripheral nerve tissue engineering: autologous Schwann cells vs. transdifferentiated mesenchymal stem cells, Tissue Eng. 12 (6) (2006) 1451-1465.

[18] L.A. Pfister, M. Papaloizos, H.P. Merkle, B. Gander, Nerve conduits and growth factor delivery in peripheral nerve repair, J. Periph. Nervous Syst. 12 (2) (2007) 65-82.

[19] A.D. Sharma, S. Zbarska, E.M. Petersen, M.E. Marti, S.K. Mallapragada, D.S Sakaguchi, Oriented growth and transdifferentiation of mesenchymal stem cells towards a Schwann cell fate on micropatterned substrates, J. Biosci. Bioeng. 121 (3) (2016) 325-335.

[20] D. Mahay, G. Terenghi, S.G. Shawcross, Growth factors in mesenchymal stem cells following glial-cell differentiation, Biotechnol. Appl. Biochem. 51 (Pt 4) (2008) 167-176.

[21] D. Mahay, G. Terenghi, S.G. Shawcross, Schwann cell mediated trophic effects by differentiated mesenchymal stem cells, Exp. Cell Res. 314 (14) (2008) 2692-2701.

[22] Y. Liang, Z. Liu, X. Shuai, W. Wang, J. Liu, W. Bi, C. Wang, X. Jing, Y. Liu, E. Tao, Delivery of cationic polymer-siRNA nanoparticles for gene therapies in neural regeneration, Biochem. Biophys. Res. Commun. 421 (4) (2012) 690-695.

[23] G. Ferrari, G. Cusella-De Angelis, M. Coletta, E. Paolucci, A. Stornaiuolo, G. Cossu, F. Mavilio, Muscle regeneration by bone marrow-derived myogenic progenitors, Science 279 (5356) (1998) 1528-1530.

[24] Y. Jiang, B.N. Jahagirdar, R.L. Reinhardt, R.E. Schwartz, C.D. Keene, X.R. OrtizGonzalez, M. Reyes, T. Lenvik, T. Lund, M. Blackstad, J. Du, S. Aldrich, A Lisberg, W.C. Low, D.A. Largaespada, C.M. Verfaillie, Pluripotency of mesenchymal stem cells derived from adult marrow, Nature 418 (6893) (2002) 41-49.

[25] B.E. Petersen, W.C. Bowen, K.D. Patrene, W.M. Mars, A.K. Sullivan, N. Murase, S.S. Boggs, J.S. Greenberger, J.P. Goff, Bone marrow as a potential source of hepatic oval cells, Science 284 (5417) (1999) 1168-1170.

[26] M.F. Pittenger, A.M. Mackay, S.C. Beck, R.K. Jaiswal, R. Douglas, J.D. Mosca, M. A. Moorman, D.W. Simonetti, S. Craig, D.R. Marshak, Multilineage potential of adult human mesenchymal stem cells, Science 284 (5411) (1999) 143-147.

[27] M. Dezawa, I. Takahashi, M. Esaki, M. Takano, H. Sawada, Sciatic nerve regeneration in rats induced by transplantation of in vitro differentiated bone-marrow stromal cells, Eur. J. Neurosci. 14 (11) (2001) 1771-1776.

[28] R. Hass, C. Kasper, S. Böhm, R. Jacobs, Different populations and sources of human mesenchymal stem cells (MSC): a comparison of adult and neonatal tissue-derived MSC, Cell Commun. Signal. 9 (2011). 12-12..

[29] D.J. Prockop, S.A. Azizi, D.G. Phinney, G.C. Kopen, E.J. Schwarz, Potential use of marrow stromal cells as therapeutic vectors for diseases of the central nervous system, Prog. Brain Res. 128 (2000) 293-297.

[30] M. Tomita, Y. Adachi, H. Yamada, K. Takahashi, K. Kiuchi, H. Oyaizu, K. Ikebukuro, H. Kaneda, M. Matsumura, S. Ikehara, Bone marrow-derived stem cells can differentiate into retinal cells in injured rat retina (Dayton, Ohio), Stem cells 20 (4) (2002) 279-283.

[31] D. Woodbury, E.J. Schwarz, D.J. Prockop, I.B. Black, Adult rat and human bone marrow stromal cells differentiate into neurons, J. Neurosci. Res. 61 (4) (2000) 364-370.

[32] A.D. Sharma, P.A. Brodskiy, E.M. Petersen, M. Dagdeviren, E.A. Ye, S.K. Mallapragada, D. Sakaguchi, High throughput characterization of adult stem cells engineered for delivery of therapeutic factors for neuroprotective strategies, Journal of visualized experiments 95 (2015) e52242.

[33] M.M. Harper, S.D. Grozdanic, B. Blits, M.H. Kuehn, D. Zamzow, J.E. Buss, R.H. Kardon, D.S. Sakaguchi, Transplantation of BDNF-secreting mesenchymal stem cells provides neuroprotection in chronically hypertensive rat eyes, Invest. Ophthalmol. Vis. Sci. 52 (7) (2011) 4506-4515.

[34] T.V. Johnson, N.D. Bull, D.P. Hunt, N. Marina, S.I. Tomarev, K.R. Martin, Neuroprotective effects of intravitreal mesenchymal stem cell transplantation in experimental glaucoma, Invest. Ophthalmol. Vis. Sci. 51 (4) (2010) 2051-2059.

[35] J.D. Kocsis, Neuroprotection and immunomodulation by cell transplantation are becoming central themes in potential therapeutic approaches for cellbased therapies, Neurosci. Lett. 456 (3) (2009) 99.

[36] K. Kurozumi, K. Nakamura, T. Tamiya, Y. Kawano, K. Ishii, M. Kobune, S. Hirai, H. Uchida, K. Sasaki, Y. Ito, K. Kato, O. Honmou, K. Houkin, I. Date, H. Hamada, Mesenchymal stem cells that produce neurotrophic factors reduce ischemic 
damage in the rat middle cerebral artery occlusion model, Mol. Ther. 11 (1) (2005) 96-104.

[37] Y. Li, M. Chopp, Marrow stromal cell transplantation in stroke and traumatic brain injury, Neurosci. Lett. 456 (3) (2009) 120-123.

[38] M. Sasaki, C. Radtke, A.M. Tan, P. Zhao, H. Hamada, K. Houkin, O. Honmou, J.D. Kocsis, BDNF-hypersecreting human mesenchymal stem cells promote functional recovery, axonal sprouting, and protection of corticospinal neurons after spinal cord injury, J. Neurosci. 29 (47) (2009) 14932-14941.

[39] L.R. Zhao, W.M. Duan, M. Reyes, C.D. Keene, C.M. Verfaillie, W.C. Low, Human bone marrow stem cells exhibit neural phenotypes and ameliorate neurological deficits after grafting into the ischemic brain of rats, Exp. Neurol. 174 (1) (2002) 11-20.

[40] W. Zheng, O. Honmou, K. Miyata, K. Harada, J. Suzuki, H. Liu, K. Houkin, H. Hamada, J.D. Kocsis, Therapeutic benefits of human mesenchymal stem cells derived from bone marrow after global cerebral ischemia, Brain Res. 1310 (2010) 8-16.

[41] N.G. Fairbairn, A.M. Meppelink, J. Ng-Glazier, M.A. Randolph, J.M. Winograd, Augmenting peripheral nerve regeneration using stem cells: a review of current opinion, World J. Stem Cells 7 (1) (2015) 11-26.

[42] S.J. Morrison, A.C. Spradling, Stem cells and niches: mechanisms that promote stem cell maintenance throughout life, Cell 132 (4) (2008) 598-611.

[43] D.T. Scadden, The stem-cell niche as an entity of action, Nature 441 (7097) (2006) 1075-1079.

[44] D.E. Discher, D.J. Mooney, P.W. Zandstra, Growth factors, matrices, and forces combine and control stem cells, Science 324 (5935) (2009) 1673-1677.

[45] A.J. Engler, S. Sen, H.L. Sweeney, D.E. Discher, Matrix elasticity directs stem cell lineage specification, Cell 126 (4) (2006) 677-689.

[46] D.J. Kelly, C.R. Jacobs, The role of mechanical signals in regulating chondrogenesis and osteogenesis of mesenchymal stem cells, Birth defects research. Part C, Embryo Today Rev. 90 (1) (2010) 75-85.

[47] R. McBeath, D.M. Pirone, C.M. Nelson, K. Bhadriraju, C.S. Chen, Cell shape cytoskeletal tension, and RhoA regulate stem cell lineage commitment, Dev. Cell 6 (4) (2004) 483-495.

[48] A.J. Steward, Y. Liu, D.R. Wagner, Engineering cell attachments to scaffolds in cartilage tissue engineering, JOM 63 (4) (2011) 74-82.

[49] S.D. Thorpe, C.T. Buckley, A.J. Steward, D.J. Kelly, European Society of Biomechanics S.M. Perren Award 2012: the external mechanical environment can override the influence of local substrate in determining stem cell fate, J. Biomech. 45 (15) (2012) 2483-2492.

[50] E. Ghafar-Zadeh, J.R. Waldeisen, L.P. Lee, Engineered approaches to the stem cell microenvironment for cardiac tissue regeneration, Lab Chip 11 (18) (2011) 3031-3048.

[51] A.J. Steward, D.R. Wagner, D.J. Kelly, The pericellular environment regulates cytoskeletal development and the differentiation of mesenchymal stem cells and determines their response to hydrostatic pressure, Eur. Cells Mater. 25 (2013) 167-178.

[52] L. Grausova, A. Kromka, Z Burdikova, A Eckhardt, B. Rezek, J. Vacik, K. Haenen, V. Lisa, L. Bacakova, Enhanced growth and osteogenic differentiation of human osteoblast-like cells on boron-doped nanocrystalline diamond thin films, PLoS ONE 6 (6) (2011) e20943.

[53] R.L. Price, K. Ellison, K.M. Haberstroh, T.J. Webster, Nanometer surface roughness increases select osteoblast adhesion on carbon nanofiber compacts, J. Biomed. Mater. Res., Part A 70A (1) (2004) 129-138.

[54] H. Cho, Y.-K. Seo, H.-H. Yoon, S.-C. Kim, S.-M. Kim, K.-Y. Song, J.-K. Park, Neura stimulation on human bone marrow-derived mesenchymal stem cells by extremely low frequency electromagnetic fields, Biotechnol. Prog. 28 (5) (2012) 1329-1335.

[55] T.J. Webster, J.U. Ejiofor, Increased osteoblast adhesion on nanophase metals: Ti, Ti6Al4V, and CoCrMo, Biomaterials 25 (19) (2004) 4731-4739.

[56] N. Huebsch, P.R. Arany, A.S. Mao, D. Shvartsman, O.A. Ali, S.A. Bencherif, J. Rivera-Feliciano, D.J. Mooney, Harnessing traction-mediated manipulation of the cell/matrix interface to control stem-cell fate, Nat. Mater. 9 (6) (2010) 518-526.

[57] S.Q. Liu, Q. Tian, J.L. Hedrick, J.H. Po Hui, P.L. Ee, Y.Y. Yang, Biomimetic hydrogels for chondrogenic differentiation of human mesenchymal stem cells to neocartilage, Biomaterials 31 (28) (2010) 7298-7307.

[58] J.S. Park, J.S. Chu, A.D. Tsou, R. Diop, Z. Tang, A. Wang, S. Li, The effect of matrix stiffness on the differentiation of mesenchymal stem cells in response to TGFbeta, Biomaterials 32 (16) (2011) 3921-3930.

[59] B.A. Allo, S.G. Lin, K. Mequanint, A.S. Rizkalla, Role of bioactive 3D hybrid fibrous scaffolds on mechanical behavior and spatiotemporal osteoblast gene expression, Acs Appl. Mater. Interfaces 5 (15) (2013) 7574-7583.

[60] A. El-Fiqi, J.H. Kim, H.W. Kim, Osteoinductive fibrous scaffolds of biopolymer mesoporous bioactive glass nanocarriers with excellent bioactivity and longterm delivery of osteogenic drug, Acs Appl. Mater. Interfaces 7 (2) (2015) $1140-1152$.

[61] H.J. Lee, W.G. Koh, Hydrogel micropattern-incorporated fibrous scaffolds capable of sequential growth factor delivery for enhanced osteogenesis of hMSCs, Acs Appl. Mater. Interfaces 6 (12) (2014) 9338-9348.

[62] H. Lv, L. Li, M. Sun, Y. Zhang, L. Chen, Y. Rong, Y. Li, Mechanism of regulation of stem cell differentiation by matrix stiffness, Stem Cell Res. Ther. 6 (1) (2015) 103.

[63] S.H. Parekh, K. Chatterjee, S. Lin-Gibson, N.M. Moore, M.T. Cicerone, M.F Young, C.G. Simon Jr., Modulus-driven differentiation of marrow stromal cells in 3D scaffolds that is independent of myosin-based cytoskeletal tension, Biomaterials 32 (9) (2011) 2256-2264.
[64] Y.S. Pek, A.C. Wan, J.Y. Ying, The effect of matrix stiffness on mesenchymal stem cell differentiation in a 3D thixotropic gel, Biomaterials 31 (3) (2010) 385-391.

[65] B.M. Baker, C.S. Chen, Deconstructing the third dimension: how 3D culture microenvironments alter cellular cues, J. Cell Sci. 125 (Pt 13) (2012) 30153024.

[66] Y. Fu, K. Xu, X. Zheng, A.J. Giacomin, A.W. Mix, W.J. Kao, 3D cell entrapment in crosslinked thiolated gelatin-poly(ethylene glycol) diacrylate hydrogels, Biomaterials 33 (1) (2012) 48-58.

[67] P.X. Ma, R.Y. Zhang, Synthetic nano-scale fibrous extracellular matrix, J. Biomed. Mater. Res. 46 (1) (1999) 60-72.

[68] W. Zeng, M.Y. Rong, X.Y. Hu, W. Xiao, F.Y. Qi, J.H. Huang, Z.J. Luo, Incorporation of chitosan microspheres into collagen-chitosan scaffolds for the controlled release of nerve growth factor, PLoS ONE 9 (7) (2014).

[69] J.D. Shao, C. Chen, Y.J. Wang, X.F. Chen, C. Du, Early stage evolution of structure and nanoscale property of nanofibers in thermally induced phase separation process, React. Funct. Polym. 72 (10) (2012) 765-772.

[70] C. Sundback, T. Hadlock, M. Cheney, J. Vacanti, Manufacture of porous polymer nerve conduits by a novel low-pressure injection molding process, Biomaterials 24 (5) (2003) 819-830.

[71] X.H. Liu, P.X. Ma, Phase separation, pore structure, and properties of nanofibrous gelatin scaffolds, Biomaterials 30 (25) (2009) 4094-4103.

[72] M. Uz, A.D. Sharma, P. Adhikari, D.S. Sakaguchi, S.K. Mallapragada, Development of multifunctional films for peripheral nerve regeneration, Acta Biomaterialia.

73] C. Fourquet_Bandeira, S.R. Montoro, T. Brocks, Chapter 1 - ThermosetThermoplastic Nanostructured Blends A2 - Thomas, Sabu, in: R. Shanks, S. Chandrasekharakurup (Eds.), Design and Applications of Nanostructured Polymer Blends and Nanocomposite Systems, William Andrew Publishing, Boston, 2016, pp. 1-13.

[74] S.M. Lien, L.Y. Ko, T.J. Huang, Effect of pore size on ECM secretion and cell growth in gelatin scaffold for articular cartilage tissue engineering, Acta Biomater. 5 (2) (2009) 670-679.

[75] K.I. Park, Y.D. Teng, E.Y. Snyder, The injured brain interacts reciprocally with neural stem cells supported by scaffolds to reconstitute lost tissue, Nat. Biotechnol. 20 (11) (2002) 1111-1117.

[76] Y.D. Teng, E.B. Lavik, X.L. Qu, K.I. Park, J. Ourednik, D. Zurakowski, R. Langer, E. Y. Snyder, Functional recovery following traumatic spinal cord injury mediated by a unique polymer scaffold seeded with neural stem cells, Proc. Natl. Acad. Sci. U.S.A. 99 (5) (2002) 3024-3029.

[77] C. Schugens, V. Maquet, C. Grandfils, R. Jerome, P. Teyssie, Polylactide macroporous biodegradable implants for cell transplantation.2. Preparation of polylactide foams by liquid-liquid phase separation, J. Biomed. Mater. Res. 30 (4) (1996) 449-461.

[78] H.A.J. Thomson, A.J. Treharne, P. Walker, M.C. Grossel, A.J. Lotery, Optimisation of polymer scaffolds for retinal pigment epithelium (RPE) cell transplantation, Br. J. Ophthalmol. 95 (4) (2011) 563-568.

[79] M. Tomita, E. Lavik, H. Klassen, T. Zahir, R. Langer, M.J. Young, Biodegradable polymer composite grafts promote the survival and differentiation of retinal progenitor cells, Stem cells (Dayton, Ohio) 23(10) (2005) 1579-88.

[80] J.H. Lee, H.K. Park, K.S. Kim, Intrinsic and extrinsic mechanical properties related to the differentiation of mesenchymal stem cells, Biochem. Biophys. Res. Commun. (2015).

81] O. Chaudhuri, L. Gu, D. Klumpers, M. Darnell, S.A. Bencherif, J.C. Weaver, N. Huebsch, H.-P. Lee, E. Lippens, G.N. Duda, D.J. Mooney, Hydrogels with tunable stress relaxation regulate stem cell fate and activity, Nat. Mater. 15 (3) (2016) 326-334

[82] S.S. Ho, K.C. Murphy, B.Y. Binder, C.B. Vissers, J.K. Leach, Increased survival and function of mesenchymal stem cell spheroids entrapped in instructive alginate hydrogels, Stem Cells Transl. Med. 5 (6) (2016) 773-781.

83] J.P. Jung, M.K. Bache-Wiig, P.P. Provenzano, B.M. Ogle, Heterogeneous differentiation of human mesenchymal stem cells in 3D extracellular matrix composites, BioResearch Open Access 5 (1) (2016) 37-48.

[84] K. Wingate, W. Bonani, Y. Tan, S.J. Bryant, W. Tan, Compressive elasticity of three-dimensional nanofiber matrix directs mesenchymal stem cel differentiation to vascular cells with endothelial or smooth muscle cell markers, Acta Biomater. 8 (4) (2012) 1440-1449.

[85] H.L. Sun, F. Zhu, O. Hu, P.H. Krebsbach, Controlling stem cell-mediated bone regeneration through tailored mechanical properties of collagen scaffolds, Biomaterials 35 (4) (2014) 1176-1184.

86] L.S. Wang, C. Du, J.E. Chung, M. Kurisawa, Enzymatically cross-linked gelatinphenol hydrogels with a broader stiffness range for osteogenic differentiation of human mesenchymal stem cells, Acta Biomater. 8 (5) (2012) 1826-1837.

[87] C. Tonda-Turo, C. Audisio, S. Gnavi, V. Chiono, P. Gentile, S. Raimondo, S. Geuna, I. Perroteau, G. Ciardelli, Porous poly( $\varepsilon$-caprolactone) nerve guide filled with porous gelatin matrix for nerve tissue engineering, Adv. Eng. Mater. 13 (5) (2011) B151-B164.

[88] P.G. di Summa, P.J. Kingham, C.C. Campisi, W. Raffoul, D.F. Kalbermatten, Collagen (NeuraGen ${ }^{\circledR}$ ) nerve conduits and stem cells for peripheral nerve gap repair, Neurosci. Lett. 572 (2014) 26-31.

[89] D. Arslantunali, T. Dursun, D. Yucel, N. Hasirci, V. Hasirci, Peripheral nerve conduits: technology update, Medical Devices (Auckland, N.Z.) 7 (2014) 405424.

[90] K. Bott, Z. Upton, K. Schrobback, M. Ehrbar, J.A. Hubbell, M.P. Lutolf, S.C. Rizzi, The effect of matrix characteristics on fibroblast proliferation in 3D gels, Biomaterials 31 (32) (2010) 8454-8464. 
[91] H. Liao, D. Munoz-Pinto, X. Qu, Y. Hou, M.A. Grunlan, M.S. Hahn, Influence of hydrogel mechanical properties and mesh size on vocal fold fibroblast extracellular matrix production and phenotype, Acta Biomater. 4 (5) (2008) 1161-1171.

[92] S.R. Peyton, C.B. Raub, V.P. Keschrumrus, A.J. Putnam, The use of poly (ethylene glycol) hydrogels to investigate the impact of ECM chemistry and mechanics on smooth muscle cells, Biomaterials 27 (28) (2006) 4881-4893.

[93] J. Lee, A.A. Abdeen, D. Zhang, K.A. Kilian, Directing stem cell fate on hydrogel substrates by controlling cell geometry, matrix mechanics and adhesion ligand composition, Biomaterials 34 (33) (2013) 8140-8148.

[94] R. McBeath, D.M. Pirone, C.M. Nelson, K. Bhadriraju, C.S. Chen, Cell shape, cytoskeletal tension, and rhoa regulate stem cell lineage commitment, Dev. Cell 6 (4) (2004) 483-495.

[95] C.R. Kothapalli, R.D. Kamm, 3D matrix microenvironment for targeted differentiation of embryonic stem cells into neural and glial lineages, Biomaterials 34 (25) (2013) 5995-6007.

[96] G.K.H. Shea, A.Y.P. Tsui, Y.S. Chan, D.K.Y. Shum, Bone marrow-derived Schwann cells achieve fate commitment - a prerequisite for remyelination therapy, Exp. Neurol. 224 (2) (2010) 448-458.

[97] A. Ladak, J. Olson, E.E. Tredget, T. Gordon, Differentiation of mesenchymal stem cells to support peripheral nerve regeneration in a rat model, Exp. Neurol. 228 (2) (2011) 242-252.

[98] B. Schlosshauer, E. Müller, B. Schröder, H. Planck, H.-W. Müller, Rat Schwann cells in bioresorbable nerve guides to promote and accelerate axonal regeneration, Brain Res. 963 (1-2) (2003) 321-326.

[99] C.A. Krekoski, D. Neubauer, J. Zuo, D. Muir, Axonal regeneration into acellular nerve grafts is enhanced by degradation of chondroitin sulfate proteoglycan, J. Neurosci. 21 (16) (2001) 6206-6213.

[100] W.L. Fodor, Tissue engineering and cell based therapies, from the bench to the clinic: The potential to replace, repair and regenerate, Reprod. Biol. Endocrinol. 1 (2003). 102-102..

[101] I. Ullah, Raghavendra B. Subbarao, Gyu J. Rho, Human mesenchymal stem cells - current trends and future prospective, Biosci. Rep. 35 (2) (2015) e00191.

[102] J. Zhang, X. Huang, H. Wang, X. Liu, T. Zhang, Y. Wang, D. Hu, The challenges and promises of allogeneic mesenchymal stem cells for use as a cell-based therapy, Stem Cell Res. Ther. 6 (1) (2015) 234.

[103] K.C. Elahi, G. Klein, M. Avci-Adali, K.D. Sievert, S. MacNeil, W.K. Aicher, Human mesenchymal stromal cells from different sources diverge in their expression of cell surface proteins and display distinct differentiation patterns, Stem Cells Int. 2016 (2016) 5646384.

[104] S. Das, F. Pati, Y.J. Choi, G. Rijal, J.H. Shim, S.W. Kim, A.R. Ray, D.W. Cho, S. Ghosh, Bioprintable, cell-laden silk fibroin-gelatin hydrogel supporting multilineage differentiation of stem cells for fabrication of threedimensional tissue constructs, Acta Biomater. 11 (2015) 233-246.

[105] P.F. Jiang, Z.W. Mao, C.Y. Gao, Combinational effect of matrix elasticity and alendronate density on differentiation of rat mesenchymal stem cells, Acta Biomater. 19 (2015) 76-84.

[106] S. Tan, J.Y. Fang, Z. Yang, M.E. Nimni, B. Han, The synergetic effect of hydrogel stiffness and growth factor on osteogenic differentiation, Biomaterials 35 (20) (2014) 5294-5306.

[107] M. Nair, D. Nancy, A.G. Krishnan, G.S. Anjusree, S. Vadukumpully, S.V. Nair, Graphene oxide nanoflakes incorporated gelatin-hydroxyapatite scaffolds enhance osteogenic differentiation of human mesenchymal stem cells, Nanotechnology 26 (16) (2015) 10.

[108] J.J. Li, B.G. Yang, Y.F. Qian, Q.Y. Wang, R.J. Han, T. Hao, Y. Shu, Y.B. Zhang, F.L. Yao, C.Y. Wang, Iota-carrageenanichitosanigelatin scaffold for the osteogenic differentiation of adipose-derived MSCs in vitro, J. Biomed. Mater. Res. B Appl. Biomater. 103 (7) (2015) 1498-1510.
[109] A. Hussain, K. Bessho, K. Takahashi, Y. Tabata, Magnesium calcium phosphate as a novel component enhances mechanical/physical properties of gelatin scaffold and osteogenic differentiation of bone marrow mesenchymal stem cells, Tissue Eng. Part A 18 (7-8) (2012) 768-774.

[110] A.J. Engler, S. Sen, H.L. Sweeney, D.E. Discher, Matrix elasticity directs stem cell lineage specification, Cell 126 (4) (2006) 677-689.

[111] R.I. Sharma, J.G. Snedeker, Biochemical and biomechanical gradients for directed bone marrow stromal cell differentiation toward tendon and bone, Biomaterials 31 (30) (2010) 7695-7704.

[112] J. Lee, A.A. Abdeen, K.A. Kilian, Rewiring mesenchymal stem cell lineage specification by switching the biophysical microenvironment, Sci. Rep. 4 (2014) 5188.

[113] R.J. Pelham, Y.-L. Wang, Cell locomotion and focal adhesions are regulated by substrate flexibility, Proc. Natl. Acad. Sci. 94 (25) (1997) 13661-13665.

[114] C.-M. Lo, H.-B. Wang, M. Dembo, Y.-L. Wang, Cell Movement Is Guided by the Rigidity of the Substrate, Biophys. J . 79 (1) (2000) 144-152.

[115] S.I. Fraley, Y. Feng, R. Krishnamurthy, D.-H. Kim, A. Celedon, G.D. Longmore D. Wirtz, A distinctive role for focal adhesion proteins in three-dimensional cell motility, Nat. Cell Biol. 12 (6) (2010) 598-604.

[116] J.S. Harunaga, K.M. Yamada, Cell-matrix adhesions in 3D, Matrix Biol. 30 (78) (2011) 363-368.

[117] K.E. Kubow, A.R. Horwitz, Reducing background fluorescence reveals adhesions in 3D matrices, Nat. Cell Biol. 13 (1) (2011) 3-5.

[118] M. Lanniel, E. Huq, S. Allen, L. Buttery, P.M. Williams, M.R. Alexander Substrate induced differentiation of human mesenchymal stem cells on hydrogels with modified surface chemistry and controlled modulus, Soft Matter 7 (14) (2011) 6501-6514.

[119] G.J. Her, H.-C. Wu, M.-H. Chen, M.-Y. Chen, S.-C. Chang, T.-W. Wang, Control of three-dimensional substrate stiffness to manipulate mesenchymal stem cell fate toward neuronal or glial lineages, Acta Biomater. 9 (2) (2013) 5170 5180.

[120] Y. Wen, B. Jiang, J. Cui, G. Li, M. Yu, F. Wang, G. Zhang, X. Nan, W. Yue, X. Xu, X. Pei, Superior osteogenic capacity of different mesenchymal stem cells for bone tissue engineering, Oral Surg. Oral Med. Oral Pathol. Oral Radiol. 116 (5) (2013) e324-e332.

[121] M.A. Schwartz, D.W. DeSimone, Cell adhesion receptors in mechanotransduction, Curr. Opin. Cell Biol. 20 (5) (2008) 551-556.

[122] T. Kobayashi, M. Sokabe, Sensing substrate rigidity by mechanosensitive ion channels with stress fibers and focal adhesions, Curr. Opin. Cell Biol. 22 (5) (2010) 669-676.

[123] J.L. Allen, M.E. Cooke, T. Alliston, ECM stiffness primes the TGF $\beta$ pathway to promote chondrocyte differentiation, Mol. Biol. Cell 23 (18) (2012) 3731 3742.

[124] Y. Sun, C.S. Chen, J. Fu, Forcing stem cells to behave: a biophysical perspective of the cellular microenvironment, Ann. Rev. Biophys. 41 (1) (2012) 519-542.

[125] D. Li, J. Zhou, L. Wang, M.E. Shin, P. Su, X. Lei, H. Kuang, W. Guo, H. Yang, L. Cheng, T.S. Tanaka, D.E. Leckband, A.B. Reynolds, E. Duan, F. Wang, Integrated biochemical and mechanical signals regulate multifaceted human embryonic stem cell functions, J. Cell Biol. 191 (3) (2010) 631-644.

[126] J. Du, X. Chen, X. Liang, G. Zhang, J. Xu, L. He, Q. Zhan, X.-Q. Feng, S. Chien, C. Yang, Integrin activation and internalization on soft ECM as a mechanism of induction of stem cell differentiation by ECM elasticity, Proc. Natl. Acad. Sci. U.S.A. 108 (23) (2011) 9466-9471.

[127] M. Brohlin, P.J. Kingham, L.N. Novikova, L.N. Novikov, M. Wiberg, Aging effect on neurotrophic activity of human mesenchymal stem cells, PLoS ONE 7 (9) (2012) e45052.

[128] K.T. Wright, K. Uchida, J.J. Bara, S. Roberts, W. El Masri, W.E.B. Johnson, Spinal motor neurite outgrowth over glial scar inhibitors is enhanced by coculture with bone marrow stromal cells, Spine J. 14 (8) (2014) 1722-1733. 